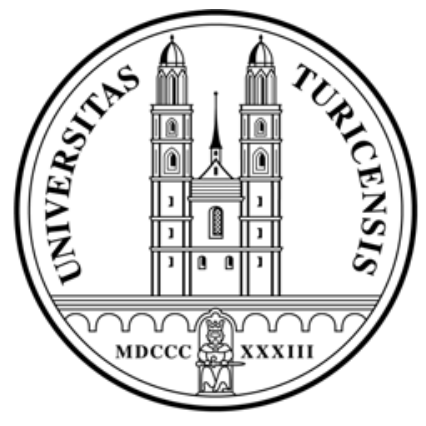

Institute for Empirical Research in Economics

University of Zurich

Working Paper Series

ISSN 1424-0459

Working Paper No. 499

Fatal Attraction?

Access to Early Retirement and Mortality

Andreas Kuhn, Jean-Philippe Wuellrich and Josef Zweimüller

August 2010 


\title{
Fatal Attraction? Access to Early Retirement and Mortality
}

\author{
Andreas Kuhn, University of Zurich and IZA* \\ Jean-Philippe Wuellrich, University of Zurich \\ Josef Zweimüller, University of Zurich, CEPR, CESifo and IZA
}

August 31, 2010

\begin{abstract}
We estimate the causal effect of early retirement on mortality for blue-collar workers. To overcome the problem of endogenous selection, we exploit an exogenous change in unemployment insurance rules in Austria that allowed workers in eligible regions to withdraw from the workforce up to 3.5 years earlier than those in non-eligible regions. For males, instrumental-variable estimates show a significant 2.4 percentage points (about 13\%) increase in the probability of dying before age 67 . We do not find any adverse effect of early retirement on mortality for females. Death causes indicate a significantly higher incidence of cardiovascular disorders among eligible workers, suggesting that changes in health-related behavior explain increased mortality among male early retirees.
\end{abstract}

JEL classification: I1, J14, J26

Keywords: early retirement, mortality, premature death, health behavior, endogeneity, instrumental variable

${ }^{*}$ We thank Joshua Angrist, David Dorn, Christian Dustmann, Pieter Gautier, Christian Hepenstrick, HansMartin von Gaudecker, Marcus Hagedorn, Christian Keuschnigg, Bas van der Klaauw, Rafael Lalive, Maarten Lindeboom, Erik Plug, Mario Schnalzenberger, Steven Stillman, Alois Stutzer, Philippe Sulger, Uwe Sunde, Fabrizio Zilibotti, participants at the Engelberg Labor Economics Seminar 2010, the Ifo/CESifo and University of Munich Conference on Empirical Health Economics 2010, as well as seminar participants in Amsterdam, Basel, Bern, Linz, Madrid and Zurich for many helpful comments and suggestions. We also thank Janet Currie, Dayanand Manoli, Kathleen Mullan and Till von Wachter for valuable discussions at an early stage of this project. Financial support by the Austrian Science Fund ("The Austrian Center for Labor Economics and the Analysis of the Welfare State") and the Research Funds ("Forschungskredit") of the University of Zurich is gratefully acknowledged. Contact: Institute for Empirical Research in Economics, University of Zurich, Mühlebachstrasse 86,8008 Zurich, Switzerland; kuhn@iew.uzh.ch; wuellrich@iew.uzh.ch; zweim@iew.uzh.ch. 


\section{Introduction}

In many industrialized countries, dramatic demographic changes put governments under increasing pressure to implement major reforms to old age social security systems. A particular focus of many reforms is to increase the retirement age by restricting access to early retirement schemes. Workers and their political representatives strongly oppose these reforms. Among the most important arguments is that after having worked all their lives in physically demanding jobs, workers should have the option to retire earlier and thus avoid emerging health problems. While leaving an unhealthy work environment is, ceteris paribus, clearly conducive to good health, the health effects of permanently exiting the labor force may go in the opposite direction. Retirement is not only associated with lower income and fewer resources to invest in one's health, but also with less cognitive and physical activity (Rohwedder and Willis, 2010) as well as with changes in daily routines and lifestyles which are potentially associated with unhealthy behavior (e.g. Balia and Jones, 2008; Henkens et al., 2008; Midanik et al., 1995; Scarmeas and Stern, 2003). In sum, the overall consequences of early retirement are not at all clear.

Among the large number of papers studying the health and mortality effects of retirement, studies adopting convincing empirical strategies to estimate the causal impact of retirement on health and/or mortality are rare. Bound and Waidmann (2007) use institutional rules governing eligibility to public pensions to identify the effect of retirement on both subjective and objective measures of physical health, by relying both on survey data and vital statistics for the UK. They find no effects, or a slightly positive influence, of retirement on health, once the possibility of endogenous entry into retirement is taken into account. Even though institutional rules offer an apparently plausible instrument for the age at retirement, the fact that workers know the exact rules may render these instruments invalid. ${ }^{1}$ Coe and Lindeboom (2008) improve on this methodology and exploit sudden and arguably unexpected changes in retirement opportunities (i.e. early retirement opportunities offered by firms to groups of workers) in the US to identify the causal effect of early retirement on men's health. They find no detrimental effects of early retirement on health and, if anything, even slightly temporary improvements. ${ }^{2}$ Charles (2002)

\footnotetext{
${ }^{1}$ For example, as Coe and Lindeboom (2008) argue, workers who know the exact legal rules they are subject to may adjust their behavior before actually retiring. Workers who are subject to different retirement rules may also differ with respect to unobserved variables, absent any behavioral responses.

${ }^{2}$ The problem with this approach is that even though firms were restricted in targeting specific groups of individuals, they were nonetheless free to choose whether to offer any early retirement window at all. It is therefore still possible that those workers who were offered any early retirement opportunity differ from those
} 
also uses age discontinuities in the financial incentives to retire, as well as legal changes to these incentives, to identify the causal effect of retirement on subjective well-being. He finds a positive effect of retirement on subjective well-being when accounting for the endogeneity of the retirement decision, while the raw correlation between age at retirement and well-being is negative. Similar results on mental well-being are reported in Neuman (2008) for the US and Johnston and Lee (2009) for the UK, and Coe and Zamarro (2008) in a cross-country study for Europe, all using survey data and a similar empirical design. Kerkhofs and Lindeboom (1997) use panel-data methods to study the effects of labor market status on the health of Dutch elderly, finding that early retirement has a positive impact on self-assessed measures of health. Another study finding a beneficial impact of retirement on health is Behncke (2009), who applies matching methods to survey data from the UK. She finds that retirement increases both the risk of a cardiovascular disease and the risk of being diagnosed with cancer. While the estimated positive effect on several health outcomes is in line with much of the medical literature (see also footnote 3), the empirical design may still suffer from endogeneity bias dues to unobserved factors (such as individuals' true health status). Qualitatively similar results are reported in Dave et al. (2008), who analyze the effects of retirement using panel-data methods and relying on survey data from the US. They find negative effects of retirement on both mental health and measures of self-assessed physical health. Note, however, that conventional panel-data methods are vulnerable to time-varying unobserved confounders such as unobserved health shocks. In sum, the available evidence uses different strategies to deal with endogenous entry into retirement and, consequently, yields no clear pattern regarding the causal impact of retirement on health. ${ }^{3}$

Our paper is also related to the literature that focuses on the impact of involuntary job loss on mortality, with respect to both research topic and methodology. An interesting recent study by Sullivan and Wachter (2009) estimates the effect of job displacement on mortality in the

${ }^{3}$ Unsurprisingly, similar ambivalence regarding the health effects of retirement is found among medical and epidemiological studies. Bamia et al. (2008) find that the risk of all-cause mortality is significantly higher for retirees than for older workers still engaged in economic activity. This finding is consistent with the results of Gallo et al. (2006), who argue that job loss increases individuals' risk of cardiovascular disease and therefore has detrimental effects on the health of older workers. Morris et al. (1994) also find increases risk of cardiovascular disease for the UK. Somewhat contrasting evidence is presented in Tsai et al. (2005) who study the effects of early retirement on mortality in a very specific sample of workers in the petrochemical industry. Similarly, Litwin (2007) finds no association between early retirement and all-cause mortality and Brockmann et al. (2009), at least when focusing on previously healthy workers only, find no effect of retirement on health.
} 
US. They find a strong impact of involuntary job loss on mortality, particularly for older (highseniority) workers and for workers who suffer large earnings losses (i.e. low-wage workers). In a related study in Sweden, Eliason and Storrie (2009) examine the impact of job loss on causespecific mortality. They find a strong increase in overall mortality among men, but no impact on females. There was, however, an increase in suicides and alcohol-related mortality for both men and women. Adverse effects of involuntary job loss on mortality are also reported in another recent study based on Norwegian data by Rege et al. (2009).

In this study, we present new evidence on the causal effect of early retirement, which we define as permanent withdrawal from the labor force before the statutory retirement age, on mortality for blue-collar workers. Blue-collar workers are an interesting group because they typically work in physically demanding jobs and because emerging health problems - and their prevention often induce these workers to retire earlier. We take advantage of a major change to the Austrian unemployment insurance system in order to overcome the problem of endogenous selection into retirement. This policy change allowed older workers who met certain eligibility criteria to withdraw from the labor market up to 3.5 years earlier than comparable non-eligible workers. This policy change was implemented in response to the international steel crisis of the mid 1980s which generated severe labor market problems in certain regions of the country. Apart from the individual's location of residence, eligibility to the program was restricted to workers aged 50 or older and those with a continuous previous work history. Exploiting regional differences in eligibility to extended unemployment benefits of otherwise eligible workers allows us to overcome the reverse-causality problem. Since the program generates variation in the effective retirement age that is arguably exogenous to individuals' health status, we can estimate the causal impact of early retirement on mortality using instrumental variable techniques. Moreover, the comparison between OLS and IV estimates allows us to assess the extent of health-driven selection into early retirement.

We find that a reduction in the effective retirement age causes a significant increase in the risk of premature death (defined in our study as death before age 67) for males, but not for females. The effect for males is not only statistically significant, but also quantitatively important. Advancing the date of permanent exit from the work force by one year causes an increase in the risk of premature death of 2.4 percentage points (a relative increase of about 13.4 percent). In line with prior expectations, we find that IV estimates are smaller than the 
simple OLS estimate, both for men and for women. This is consistent with negative health selection into retirement and underlines the importance of a proper identification strategy when estimating the causal impact of early retirement on mortality. Our results indicate no causal effect of early retirement on mortality for females. The association between retirement age and mortality indicated by the OLS estimate is therefore due to negative health selection into retirement. One reason why only male but not female blue-collar workers suffer from early retirement may be that women are more capable of coping with retirement; they may be more active after permanently exiting the labor market due to their higher involvement in household activities (note that we examine cohorts in the empirical analysis for which the traditional role pattern was still dominant). Giving up the job is associated with loss of social status and identity for the main breadwinner, while work (and giving it up) is not central in life for the additional income earner. Moreover, women may be more health-conscious and adopt less unhealthy behaviors like smoking and drinking, for example.

We consider two specific channels for understanding the reasons why male early retirees die earlier. A first channel suggests that early exit from the labor market is associated with lower permanent income. We find that earnings losses due to early retirement cannot explain our finding for men, because these losses are too small in size to have a substantial impact on mortality. A second channel of potential relevance in the present context are changes in healthrelated behaviors associated with smoking, drinking, and a low level of physical exercise. To learn about the potential importance of changes in health-related behavior, we look at causes of the death, in particular due to cardiovascular causes commonly associated with changes in health behavior. We show that early retirees have a significantly higher risk of dying from a cardiovascular cause, consistent with an explanation based on changes in health-related behavior among early retirees. Finally, we present some evidence that supports the view that the voluntariness of the retirement decision has an impact on the health effects of early retirement.

Our study goes beyond the existing literature on several dimensions. First, we have access to a very large administrative data set containing precise and reliable information on both the timing of retirement and the date of death. Austrian social security data are collected for the purpose of assessing individuals' eligibility to and level of old age social security benefits. Information on any individual's work history and the date of his or her death is thus precise. Biases induced by measurement error are therefore unlikely. As a result, we are able to estimate 
the impact of early retirement on mortality, while most studies thus far focused on subjective measures of health or well-being. ${ }^{4}$ Second, the data contains virtually the universe of bluecollar workers in the private sector in Austria. This results in a sufficiently large number of observations and very precise estimates. This is a particular advantage in the present context, because many previous studies (mostly those based on survey data) often face the problem of imprecise estimates due to too small a sample size. Third, our empirical strategy is based upon a policy change that, arguably, generated vast exogenous variation in the potential minimum age of permanently leaving the labor force. While treated and control groups are ex-ante similar in observable characteristics, the group of eligible individuals retires between 9 and 12 months earlier than the group of non-eligible individuals. In sum, our study is based on high-quality data with a precise and objective measure of physical health, a large number of observations, and an empirical strategy that exploits sizable exogenous variation in individuals' retirement age.

While our empirical design is based on a policy change in one rather small country, namely Austria, we think that our results are of more general interest. First, Austria is one of the countries with the highest incidence of early retirement. In 2003, labor force participation rates among workers aged 55 to 64 was as low as $42.3 \%$ for men and $20.0 \%$ for women, respectively (OECD, 2004). The fact that early retirement is so common means that early retirees are not a specific group but rather a representative part of the entire population. Second, gross replacement rates are relatively high, so the loss of permanent income associated with early retirement is comparatively low (Koch and Thimann, 1999; OECD, 2007). Income changes associated with early retirement should therefore only play a minor role. Finally, there is universal coverage by the public health care system. All early retirees have access to exactly the same basic health care services as employed individuals. In sum, our empirical design mainly captures the direct effect of withdrawing from the labor force on mortality, rather than indirect effects, such as those due to a loss of income or access to health insurance.

The remainder of this paper is structured as follows. In section 2 we discuss the relevant

\footnotetext{
${ }^{4}$ The distinction between subjective and objective measures appears to be of special importance (Bound, 1991), as even self-reported measures of physical health may be subject to considerable reporting error (Baker et al., 2004). It is likely that truly subjective measures of health, i.e. individuals' assessment of their well-being, perform even worse because of ex-post justification bias and similar effects. Indeed, studies using subjective health measures tend to find beneficial effects of retirement while the evidence is less consistent for objective health measures. It is also conceivable that there is considerable measurement error with respect to retirement age, especially in survey data, whereas such error is arguably of minor importance in administrative data.
} 
institutional background and how changes in the unemployment insurance made early retirement easier for some groups of workers. We then discuss our data source, detail how we have selected our sample and present descriptive statistics in section 3. Details of our econometric framework are given in section 4 . Our key results are presented and discussed in section 5 . In section 6 , we focus on potential channels explaining excess mortality among male retirees. Finally, section 7 concludes.

\section{Pathways to Retirement in Austria}

\subsection{The Retirement System}

Almost all workers in Austria are covered by the public pension insurance system, and public pension benefits are the most important source of income for most retirees (OECD, 2007). The level of old age pension benefits depends on retirement age, the contributions (i.e. earnings) made to the system in the years before retirement as well as on the number of contribution months (i.e. work experience). ${ }^{5}$ The maximum gross replacement rate for a worker retiring at the statutory retirement age in the year 1993 was $80 \%$ of his or her previous earnings, given a continuous work history with 45 insurance years before retiring. Pension benefits are subject to income tax and mandatory health insurance contributions. The regular statutory retirement is age 65 for men and age 60 for women. For workers with long-insurance duration, the statutory retirement age (statutory retirement age with with long-insurance duration) is age 60 for men and age 55 for women. Eligibility to statutory retirement with long-insurance duration is linked to an individual's previous work history: workers who paid social security contributions for at least 35 years and who worked at least 2 out of the 3 years prior to retirement have the option to retire early at age 60 for men and at age 55 for women.

There are several pathways into regular (early or late) retirement. The first pathway is obviously the direct transition from employment to retirement. A second pathway is the indirect transition from employment to retirement via the unemployment system. Individuals become eligible for regular retirement benefits at age 60 after having drawn regular unemployment benefits and/or means-tested unemployment assistance for at least 12 out of the previous 15 months

\footnotetext{
${ }^{5}$ There were several changes to the pension system during our observation period, most notably in 1993 and in 2000. However, all these changes affected all workers (i.e. both our control and treatment group, see below) in the same way and thus need not be taken explicitly into account. See Hofer and Koman (2006) for details.
} 
("vorzeitige Alterspension wegen langer Versicherungsdauer"). An unemployed person aged 50 or older could draw regular unemployment benefits for a maximum period of 52 weeks (30 weeks before August 1989) with a replacement rate of 40-60\%. Unemployment assistance payments may, in principle, last for an indefinite time period. Alternatively, unemployed individuals who had paid social security contributions for at least 15 out of the last 25 years are also eligible to regular early retirement benefits at age 60 after a period of 12 months in special income support ("Sonderunterstützung"), which is equivalent to an unemployment spell in legal terms, but with $25 \%$ higher benefits. Note that individuals who were eligible to special income support could also combine unemployment benefits and special income support by claiming first the former followed by the latter. These pathways via the unemployment system essentially allowed workers to withdraw from the work force at age 59 and bridge the gap until regular early retirement benefits via an unemployment spell of 12 months. The third pathway is via disability insurance, which allows workers to withdraw from the work force before the regular early retirement age. This latter pathway becomes more feasible after age 55 when eligibility rules to disability benefits become significantly relaxed (Hofer and Koman, 2006). ${ }^{6}$

\subsection{The Regional Extended Benefit Program}

To assess the causal effect of early retirement on mortality, we exploit a policy change to the Austrian unemployment insurance system that introduced a further pathway to retirement, the Regional Extended Benefit Program (REBP). The REBP allowed eligible workers to effectively withdraw from the labor force as much as 3.5 years earlier than non-eligible workers. The REBP was introduced in response to the steel crisis of the late 1980s which hit certain regions of the country particularly hard. To mitigate economic hardship in these regions, the Austrian government enacted a change in the unemployment insurance law that granted access to unemployment benefits (UB) for up to 209 weeks. $^{7}$ To become eligible, a worker had to fulfill the following three criteria at the time of unemployment entry: (i) age 50 or older, (ii) a continuous work history before becoming unemployed (i.e. 780 weeks of employment in the last 25 years

\footnotetext{
${ }^{6}$ After age 55, disability benefits could be drawn when an individual's work capacity within his or her main occupation is reduced by more than 50 percent of that of a healthy individual. Before age 55, a reduction of the individual's general work capacity, not restricted to a particular occupation, is required for eligibility to a disability pension.

${ }^{7}$ Previous econometric evaluations of the REBP have found large effects of the program on realized unemployment duration (Lalive, 2008; Lalive and Zweimüller, 2004a,b; Winter-Ebmer, 1998).
} 
preceding the unemployment spell), and (iii) at least 6 months of residence in one of the eligible regions. The program was enacted in June 1988 and remained in force until July $1993 .{ }^{8}$ In contrast, workers aged 50 or older who were not eligible to the REBP were entitled to a maximum of 52 weeks of regular unemployment benefits (to only 30 weeks before August 1989).

Figure 1 about here

Figure 1 summarizes the institutional design of our study. The figure makes clear that individuals eligible to the REBP could effectively withdraw from the labor force at age 55 (men) or 50 (women) by claiming unemployment benefits for the maximum duration of 4 years, followed by one full year of special income support. This is different for workers not eligible to the REBP. These workers had the option of effective retirement at age 58 or 58.5 (men) and 53 or 53.5 (women), also by bridging the time until the regular early retirement age by the maximum duration of unemployment benefits of 52 weeks after August 1989 or 30 weeks before August 1989 .

\section{Data and Sample}

\subsection{Data Source}

We use individual register data from the Austrian Social Security Database (ASSD), described in more detail in Zweimüller et al. (2009). The data cover the universe of Austrian wage earners in the private sector and collects, on a daily basis, workers' complete labor market and earnings history which we observe up to the year 2006. The data also contain a limited set of socioeconomic characteristics (year and month of birth, age, sex, general occupation) and additional information on the firms where the workers were employed. The administrative purpose of collecting these data is to provide all the information necessary for calculating old age social security benefits.

The data contain precise information on the date of retirement and on mortality (date of death). Information on mortality is observable up to the year 2008. Moreover, the data contain information necessary for determining an individual's eligibility to the REBP. This latter

\footnotetext{
${ }^{8}$ Initially 28 out of about 100 labor market districts were eligible to extended unemployment benefits. The REBP underwent a reform in January 1992 that excluded 6 formerly eligible regions from the program. Moreover, eligibility criteria were tightened, as not only location of residence but also the individual's workplace had to be in a REBP region (see section 3.2 for details).
} 
information is of crucial importance because we want to exploit the exogenous variation in the retirement age that the program induces, i.e. we will use eligibility status as an instrument for the retirement age. We use information on individuals' month of birth and employment history to determine whether a worker meets the age and employment criteria set by the REBP. However, we do not observe the place of residence. To proxy community of residence we use the community of work. While this introduces some measurement error due to the false classification of REBP eligible workers as non-eligible and vice versa, we find that this is not a major drawback, as most individuals work in the same labor market district where they live. ${ }^{9}$

\subsection{Sample Selection}

\section{Workers}

First, we restrict the analysis to blue collar workers. ${ }^{10}$ The main reason for our focus on blue collar workers is that the REBP was a program targeted towards regions with a high dominance of blue collar workers. While the program was, in principle, also available to white collar workers, effective take-up by white collars was weak. ${ }^{11}$

We further restrict the sample to workers who meet the age criteria sometime during the period the REBP was in effect and who had a continuous work history before reaching the age of 50. We first turn to the age criteria. The age criterion is achieved by only considering men born between July 1929 and December 1941 and women born between July 1934 and December 1941, respectively. ${ }^{12}$ This ensures that these individuals eventually attain age 50 during the REBP and men (women) are aged 59 (54) or less when the program was introduced. Put differently,

\footnotetext{
${ }^{9}$ We can check the extent of measurement error introduced by this proxy since we can observe the place of residence for individuals on unemployment benefits. We correctly assess REBP-eligibility for more than $90 \%$ of all individuals in this subsample if place of work instead of place of residence is used to assess REBP eligibility.

${ }^{10}$ Because blue and white collar workers in Austria are partially subject to different social security rules (for example, there are differences in notice periods and the duration of sick leave benefits), we can determine workers' occupational status without any significant measurement error.

${ }^{11}$ In fact, eligibility status is a highly significant predictor of early retirement among blue collar workers, but not among white collar workers. One potential explanation is that blue collar (low income) workers face higher replacement rates than white collar (higher income) workers when unemployed and thus higher incentives for taking advantage of the program. Specifically, replacement rates (both with respect to unemployment benefits and early retirement benefits) are much lower for white collar workers due to earnings caps. Because the instrument is too weak, results remain inconclusive in the case of white collar workers (results for white collar workers are available upon request).

${ }^{12}$ In principle, we could also consider the cohorts born from January 1942 to July 1943 as they (eventually) meet the age criteria as well. However, the data available to us from the ASSD only tracks individuals' labor market histories up to 2006. We omit cohorts born later than December 1941 in order to observe individuals' labor market histories at least until age 65 (i.e. men's statutory retirement age).
} 
these cohorts are in principle able to use the program to retire earlier if they meet all eligibility criteria (recall that men (women) can claim special income support as soon as they turn 59 (54)), but not all of them could take full advantage of the program. For instance, males born between 1934 and 1938 could take full advantage of the REBP because they reached age 55 during the time the REBP was in place. In contrast, males born before 1934 were too old to take full advantage (i.e. they already were 56 years old when the REBP started) and cohorts born after 1939 were too young (i.e. they were younger than 55 when the REBP was abolished). Now we turn to the work experience criterion. To select workers who meet the REBP work experience criterion, we include only those workers with a sufficiently continuous work history at age 50 (i.e. workers with at least 15 employment years during the last 25 years). Furthermore, we only consider individuals with at least one employment year during the last two years at age 50, a requirement for being eligible to draw unemployment benefits. Because all selected individuals meet both the age and the employment criteria, the assessment of whether or not a worker is eligible to extended UB entitlement entirely hinges on individuals' place of residence (proxied by place of work; see footnote 9). This means that by using REBP eligibility as instrument for the retirement age, we basically compare individuals who work in eligible districts with those who work in non-eligible districts (section 4 provides the details).

Finally, we drop workers from the steel sector because our instrument does not induce changes in the retirement age for these workers. The reason is that, apart from the REBP, there was a second important measure to alleviate the problems associated with mass redundancies in the steel sector, the "steel foundation". This program was available both in treated and in control regions. Firms in the steel sector could decide whether to join, in order to provide their displaced workers with state-subsidized re-training measures organized by the foundation. Member firms had to co-finance this foundation. Displaced individuals who decided to join this outplacement center were entitled to claim regular unemployment benefits for a period of up to 3 years (later 4 years), regardless of age and place of residence (see Winter-Ebmer, 2001, for an evaluation of the steel foundation). We therefore do not find any difference in the retirement age between steel-workers in eligible and non-eligible regions. 


\section{Regions}

Figure 2 shows the geographical distribution of treated and control regions at the community level: communities shaded in green (red) were (were not) eligible for the REBP. We can see that the group of regions eligible to the program stretches from the northern to the southern border of Austria and encompasses a coherent area encompassing communities from different states: Lower and Upper Austria in the north, Styria in the center, Burgenland in the southeast, and Carinthia in the south.

Figure 2 about here

To make sure that potential differences in labor market conditions between treated and control regions do not contaminate our empirical estimates, we contrast only those eligible and non-eligible districts that are adjacent to each other and economically similar. We use the common classification of territorial units for statistics (NUTS). NUTS comes in three aggregation levels, of which we choose the most disaggregated one (NUTS-3). ${ }^{13}$ We further confine our sample to those NUTS-3 regions that contain both eligible and non-eligible districts. Since NUTS-3 regions comprise geographically adjacent districts and because these units are quite small, this procedure implies that differences in labor market conditions between treated and control regions are unlikely to affect our analysis. ${ }^{14}$ Figure 2 highlights the communities within those eight NUTS-3 units that we actually consider in the empirical analysis. The darker-shaded areas in green denote non-eligible communities and the darker-shaded areas in red denote eligible communities within these NUTS-3 units, respectively. The remaining communities, i.e. those shaded in light green and light red, respectively, denote eligible and non-eligible communities which are not considered in the analysis.

\footnotetext{
${ }^{13}$ NUTS-3 units are defined in terms of the existing administrative units in the EU member states. An administrative unit corresponds to a geographical area for which an administrative authority has power to take administrative or policy decisions in accordance with the legal and institutional framework of the member state. There are 35 distinct NUTS-3 units in Austria, each consisting of one or more district(s) ("Bezirk(e)").

${ }^{14}$ However, the map also shows that treated regions were not selected randomly. Even though we think that there is no strong a-priori reason for believing that individuals' health status was decisive in determining a given community's treatment status, we will return to this issue later (see section 4 below). See also the discussion in Winter-Ebmer (1998) and Lalive and Zweimüller (2004a,b) on how the regions were selected for eligibility in the first place. Importantly, Lalive and Zweimüller (2004a) show that both employment and unemployment rates for (potentially) eligible workers were quite similar before the start of the program. However, they also show that the program significantly increased the risk of unemployment for older workers, suggesting that the program may have been used deliberately as a path into early retirement, especially for women (Lalive, 2008). Indeed, our results on the first-stage effect of the program are perfectly in line with this finding (see section 5 below).
} 


\subsection{Key Measures}

The key variables are our measures of early retirement and mortality. As explained, our empirical design uses only cohorts born between 1929 and 1941 (men) and 1929 and 1934 (women), respectively. Because, at the same time, the information on labor-market histories ends in December 2006 and because the mortality information is only available up to July 2008, individual labor-market histories of workers included in the sample can be tracked (at least) up to their 65th birthdays and individuals' mortality-related information is available (at least) up to their 67 th birthdays. We use this to define our dependent variable indicating premature death, a dummy variable that indicates whether a worker died before reaching age $67 .{ }^{15}$

To be included in our sample, a worker must still be alive at age 50 and must meet the REBP age and experience criteria. Hence our mortality indicator measures whether or not an individual in our sample dies between age 50 and age 67 . This is a meaningful indicator in the present context. Since we are studying birth cohorts 1941 and older, we are considering individuals whose life expectancy is still quite low (see footnote 15). Moreover, we look at bluecollar workers whose life expectancy is lower than that of white-collar workers. In our sample, the probability of death before age 67 is 18.0 percent for males and 7.2 percent for females.

Our treatment variable is the number of early retirement years. This variable measures the time span between the statutory retirement age at age 65 (for men) and 60 (for women), respectively, and the date when the individual permanently withdraws from working life. More precisely, we define the date of retirement as the day after the end of the individual's last regular employment spell. ${ }^{16}$ Hence a positive number on the endogenous variable denotes that an individual has retired before the statutory retirement age. Throughout the analysis, we will stratify the sample by gender because male and female retirement and mortality patterns are very different.

\footnotetext{
${ }^{15}$ One might object that this measure is ill-suited for studying mortality because it only covers deaths occurring between age 50 and age 67 . Note, however, that life expectancy at birth was not yet very high for those birth cohorts considered in the analysis. In fact, according to the life table based on data from 1930/33, life expectancy at birth (at age 45) was 54.5 (24.7) years for men and 58.5 (27.0) years for women (figures taken from Statistics Austria).

${ }^{16}$ Note that our indicator does not require the individual to be a retiree in the legal sense of drawing regular old age social security benefits. Instead, our definition of effective retirement hinges upon the last day of employment and does not refer to a particular transfer an individual gets after ceasing work permanently. Effectively retired individuals draw unemployment benefits, disability benefits, old-age social security benefits, some other type of benefit, or no transfer.
} 


\subsection{Descriptive Statistics}

Table 1 shows descriptive statistics for our two different subsamples and by eligibility status. Our sample consists of 17,590 blue-collar males and 3,283 blue-collar females of whom 18.0 percent and 7.2 percent die before age of 67 , respectively. Next, the table shows that male workers in eligible districts retire 0.75 years (9 months) earlier than their colleagues in noneligible regions. This is strong prima-facie evidence that male workers use the REBP as an indirect channel into early retirement. The situation is even more pronounced for females, who retire 1.15 years (14 months) earlier in treated than in control regions.

Table 1 about here

Table 1 also shows that the treated and control samples are well balanced (though not identical) with respect to observable characteristics. Columns (1) to (4) shows almost no difference in average (and variance of) age, indicating the absence of any major differences in age composition of the blue collar workers between the two types of regions. The various variables describing the previous work experience indicate slightly higher work experience before age 50 in non-eligible regions; the difference is rather small, however. Interestingly, blue collar workers in eligible regions were slightly less often on sick leave before age 50 than workers in control regions. Moreover, male blue collar workers in treated regions earned higher wages before age 50 (average earnings at ages 43 to 49 ) than those in control regions. We also see that the industry mix between regions is similar but not identical. There is a somewhat higher fraction of manufacturing workers in treated regions, and a somewhat larger fraction of construction and agriculture workers in control regions. In sum, treated and control groups are similar but not identical with respect to observable characteristics. Controlling for remaining differences in worker characteristics and in industry structure might therefore be important in the empirical analysis below.

Columns (5) to (8) show analogous descriptive statistics for female blue collar workers. It turns out that the differences across regions among females are very similar to those among males. There is only a negligible difference in age and experience indicators. However, females in treated regions have a lower incidence of sick days, they earn higher wages than blue collar females in control regions, and are more concentrated in the manufacturing sector than bluecollar females in control regions. 


\section{Econometric Framework}

Estimating the causal effect of early retirement on health and mortality is difficult because poor health is a key determinant in individuals' retirement decisions (e.g. Disney et al., 2006; Dwyer and Mitchell, 1999). As a result, simple OLS estimates of a regression of individuals' mortality risk on an indicator of early retirement will likely overestimate the true causal effect of early retirement on mortality. We now detail how we deal with this issue.

To fix ideas, let $Y_{i}$ denote a dummy variable indicating death before age 67 (such that $Y_{i}$ takes on the value 1 in the event of death before age 67 , and 0 otherwise) and let $D_{i}$ denote the number of years spent in early retirement. That is, $D_{i}$ measures the difference between the statutory and actual retirement age such that positive values correspond to exit from the labor force before the statutory retirement age. Our regression model of interest can then simply be written as

$$
Y_{i}=\beta_{0}+\beta_{1} D_{i}+X_{i} \beta+\epsilon_{i},
$$

where $X_{i}$ denotes additional control variables and $\epsilon_{i}$ is the error term. We are interested in estimating parameter $\beta_{1}$, the causal effect of early retirement years (i.e. the number of years between the last day in regular employment and the statutory late retirement age) on premature death (i.e. death before age 67). Since workers self-select into early retirement based on factors that are not observed in the data, e.g. unobserved health shocks, $D_{i}$ is endogenous and thus the simple OLS estimate of $\beta_{1}$ is biased.

\subsection{Identification}

Our empirical design tackles reverse causality by exploiting the exogenous variation in the date of permanent exit from employment generated by the REBP. As we explained, the REBP allowed eligible workers in treated regions to advance permanent withdrawal from employment by up to 3.5 years. To assess the causal relationship between early retirement and mortality, we use an instrumental variable (IV) approach. Using this empirical strategy, we estimate the causal effect for those individuals whose date of permanent exit from employment is affected by their eligibility to the REBP, i.e. we use workers' REBP eligibility as an instrument for their actual retirement age (e.g. Angrist et al., 1996; Imbens and Angrist, 1994). The credibility of our empirical strategy crucially hinges upon the assumption that our instrument is "as good as 
randomly assigned". In other words, REBP eligibility should be uncorrelated with unobserved variables that are associated with retirement age and that simultaneously affect the probability of premature death. REBP eligibility was not randomized but a function of age, previous work experience, and location of residence. Hence REBP eligibility should be considered to be conditionally randomized, where the conditioning is done on the eligibility criteria mentioned above. ${ }^{17}$ Since the age and experience criteria are fulfilled by construction of the selected sample, the question of whether our instrument is valid or not essentially boils down to the question of whether the risk of premature death is correlated with individuals' regions of residence in the absence of the program (an issue that we take up in section 4.2 below).

An equivalent way of thinking about our empirical design is to consider the eligibility criteria, $Z_{i}$ as a deterministic function of a worker's age, work experience, and his or her location of residence. From this perspective, we have to argue that each of these indicator functions is exogenous from an individual's standpoint. Otherwise, it would be possible for an individual to manipulate one (or more) of the variables determining eligibility and thus indirectly manipulate his or her eligibility status. Age and previous work experience are unlikely to be endogenous in the present context. ${ }^{18}$ However, endogenous mobility across regions may be a real issue. For example, workers may move from non-eligible districts to eligible districts in order to become eligible for the program. While this is a potential problem, it is mitigated by the fact that eligibility rules require residence in a treated region of at least 6 months prior to claiming unemployment benefits. Moreover, mobility is rather uncommon among older workers in Austria. In 1991, for example, only 3 percent (4 percent) of individuals aged 55-59 (50-54) had moved across districts within states or across states within the last 5 years. ${ }^{19}$ This suggests that the type of mobility that would cause worries for our empirical strategy is actually a rather negligible

\footnotetext{
${ }^{17}$ Introducing covariates into the heterogeneous effects model technically calls for the semi-parametric procedure proposed by Abadie (2003). However, no extension of this procedure for models with variable treatment intensity yet exists (i.e. age at retirement is a continuous variable). On the other hand, however, Angrist (2001) argues that 2SLS is likely to give a good approximation to the causal relationship of interest in many cases (i.e. the Abadie procedure is identical to 2SLS when the first stage is linear).

${ }^{18}$ Age can clearly be considered as exogenous in our setting. The employment criteria may be subject to an endogeneity issue if individuals improve their work history in order to become eligible for the program. However, we restrict the sample to individuals with an almost continuous work history (recall from Table 1 that the workers in our sample have on average more than 20 employment years during the last 25 years). Since the REBP was only announced shortly before coming into force and was in place for only 5 years, the workers in our sample fulfilled the employment criteria even without altering their work behavior.

${ }^{19}$ The Austrian census asks individuals whether they moved in the past 5 years. According to these data, $88 \%$ did not move at all, $5 \%$ moved within communities, $1 \%$ moved across communities within district, and $2 \%$ immigrated from abroad (figures are from census data, Statistics Austria).
} 
phenomenon.

Another related problem may arise if location of residence has per se an effect on individuals' mortality risk. Location of residence is a REBP eligibility criterion. Conditioning on place of residence at the district level is thus not feasible, since it is perfectly correlated with our instrument. To circumvent this potential problem, we included only those NUTS-3 regions in our sample that comprise both districts eligible to the REBP and those that are not so. If neither mortality risk nor the duration of early retirement is governed by REBP-eligibility status within any NUTS-3 unit, the independence assumption likely holds, ensuring the validity of our instrument. ${ }^{20}$

The specification of the first-stage regression remains. Based on the previous discussion, we assume that the following equation determines the duration of early retirement

$$
D_{i}=\alpha_{0}+Z_{i} \alpha_{Z}+\sum_{j} C_{i j} \alpha_{C j}+\sum_{k} E_{i k} \alpha_{E k}+\sum_{l} N_{i l} \alpha_{D l}+X_{i} \alpha+\varepsilon_{i}
$$

where, as before, the endogenous variable $D_{i}$ corresponds to the number of years spent in early retirement. $Z_{i}$ is our binary instrument, denoting whether an individual was eligible (in which case $\left.Z_{i}=1\right)$ or not eligible $\left(Z_{i}=0\right)$ to the REBP. The variables $C_{i j}, E_{i j}$, and $N_{i l}$ refer, respectively, to the workers' date of birth, previous work experience, and NUTS-3 unit of residence, i.e. the three eligibility criteria of the program. ${ }^{21}$ We also include additional control variables denoted by $X_{i}$ in some specifications. ${ }^{22}$ These additional controls increase the precision of our estimates and are helpful in underlining the credibility of our empirical strategy by showing that these additional controls do not have an effect on the 2SLS estimates.

\footnotetext{
${ }^{20}$ Three additional assumptions are needed, and they are likely to be fulfilled. First, we have to assume that the only channel through which REBP eligibility has an impact on premature death is through its impact on the duration of early retirement. Thus the instrument must not have any direct effect on the dependent variable. We believe that this assumption holds in the present context, as it is difficult to imagine that the mere eligibility to extended benefits should have any direct effect on health and mortality. Second, we assume that the instrument has a monotone impact on the endogenous variable. In our context, we have to assume that REBP eligibility induced some individuals to retire earlier than in the absence of eligibility, and that no individual decided to retire later because of REBP eligibility. Although we cannot test this assumption, we think it is quite unlikely that this assumption fails in our application. Finally, the REBP eligibility must have an effect on the early retirement date (i.e. the date when individuals permanently leave the labor force). We show in some detail that this is indeed the case in section 5.1.

${ }^{21}$ Specifically, $j$ indexes half-year-of-birth and runs from $1929 \mathrm{~h} 2$ to $1941 \mathrm{~h} 2$ for men and from $1934 \mathrm{~h} 2$ to $1941 \mathrm{~h} 2$ for women; $k$ refers to the past $1,2,5,10$, and 25 years (before age 50); and $l$ indexes those 8 NUTS-3 units included in the analysis. For work experience, we also include squared terms.

${ }^{22}$ The list of additional control variables is as follows: Several terms counting the number of past days on sick leave (also indexed by $k$ ) and the corresponding squared terms, employers' industry affiliation (14 industries), the log of the average of yearly earnings between ages 43 and 49 , and the log of the standard deviation of yearly earnings between ages 43 and 49 .
} 
Finally, notice that the REBP was only in effect for a limited period of time. This implies that the various birth cohorts differ in the extent to which the REBP actually offered a pathway to early retirement. For instance, birth cohort 1930 was already 58 years old at the date when the REBP was implemented. In contrast, birth cohort 1933 was 55 years old when the REBP started. The former cohort could take only limited advantage of the program (retiring at age 58), whereas the latter cohort could take full advantage of the program (by already retiring at age 55), as the actual benefits stemming from the program depend on an individual's date of birth. To capture the heterogeneity in the effect of the instrument on the first-stage outcome, we allow for cohort-specific effects by including interaction terms between the eligibility indicator and year-semester of birth into the first-stage equation

$$
D_{i}=\alpha_{0}+\sum_{j}\left(Z_{i} \cdot C_{i j}\right) \alpha_{Z j}+\sum_{j} C_{i j} \alpha_{C j}+\sum_{k} E_{i k} \alpha_{E k}+\sum_{l} N_{i l} \alpha_{N l}+X_{i} \alpha+\varepsilon_{i},
$$

which implies that we now have 25 instruments for our male cohorts (1929h2-1941h2) and 15 instruments for our female cohorts (1934h2-1941h2), respectively.

\subsection{Assessing Instrument Validity}

As we have explained, our key identifying assumption is that location of residence in either a treated or a control region is exogenous with respect to individuals' health status. We now provide two pieces of evidence supporting the validity of our instrument.

Table 2 about here

First, Table 2 shows the estimates of a regression of standardized mortality rates at the district level for the years 1978-1984, well before the REBP was implemented. We explore differences in standardized mortality rates at the district level for four different age groups, separately for men (columns (1) to (4)) and women (columns (5) to (8)). The table shows estimates from a simple regression of (district-specific) log standardized mortality rates on a dummy indicating eligible districts. It turns out that standardized mortality rates did not differ between eligible and non-eligible districts before the REBP started. The relevant point estimate turns out to be both statistically and quantitatively insignificant.

Table 3 about here 
The second piece of evidence makes use of individual-level information on workers' days on sick leave provided by the ASSD. This is a good proxy for workers' ex-ante health condition. We measure the number of sick leave days before the individual turns age 50, i.e. immediately before he or she meets the age criterion on the REBP. To assess whether eligible and noneligible individuals have ex-ante similar health conditions, we regress the number of sick leave days on our binary instrument $Z_{i}$ while controlling for cohort fixed-effects, experience, NUTS-3 fixed-effects, industry fixed-effects, and earnings. Table 3 shows reduced-form results for four different counts of sick leave days, for male and female workers separately. Irrespective of the length of retrospective information used for the sickness indicator, it turns out that workers' health conditions do not systematically differ between eligible and non-eligible individuals within the same NUTS-3 units, and this is valid for both men and for women.

Taken together, we think that the evidence presented in Tables 2 and 3 provides strong support for our claim that the selection of eligible labor-market districts was unrelated to mortality in these districts.

\section{Results}

\subsection{First-Stage Results: REBP Eligibility and Early Retirement}

A first look at descriptive statistics in section 3.4 above shows that both males and females withdraw substantially earlier from the work force in eligible regions. We proceed by presenting first-stage estimates of equations (2) and (3), respectively. Results are given in Table 4 for men and Table 4 for women, respectively. We will first discuss the results for males.

Tables 4 and 5 about here

We show estimates for four different regression specifications. Columns (1) and (2) estimate one common effect of the instrument on the endogenous variable, while columns (3) and (4) allow for a varying effect across birth cohorts. Columns (1) and (3) control for cohort fixed-effects, past work experience, and NUTS-3 fixed-effects; columns (2) and (4) additionally include past sick leave days, the average and standard deviation of yearly earnings (during ages 43 to 49), and industry fixed-effects. 
We start with the just-identified case (i.e. estimates of equation (2)), shown in the first two columns of each table. For males, the common first-stage effect of the instrument amounts to 0.71 years. This means that REBP-eligibility lowers the effective age of retirement by roughly 8.5 months. If we add further controls in column (2), the effect of the instrument is somewhat reduced to 0.59 years (roughly 7 months). Table 5 reports corresponding results for female workers. The first stage effect averaged across birth cohorts amounts to 1.01 years in the first specification and is only slightly reduced to about 0.94 years when additional controls are included (see column (2) of Table 5).

Figure 3 about here

Next, we turn to the over-identified case, given by equation (3) above. The overall pattern becomes more apparent in a graph. Figure 3 displays the relevant parameter estimates, $\hat{\alpha}_{Z j}$, per year-semester cohort (these estimates correspond to those displayed in column (3) of Table 4). The underlying regressions control for cohort fixed effects (one for each year-semester cohort), work experience, and NUTS-3 fixed-effects. Panel (a) shows that the first-stage effect is small for older cohorts and becomes increasingly larger for younger cohorts. This is exactly what we expect, given the REBP rules. Cohorts born in 1929 were already close to 60 years old when the REBP was implemented. Consequently, the REBP cannot have had a sizable impact on the date of permanent exit from the work force for them. The figure shows that the strongest impact is observed for cohorts born in 1934 or later, who could take full advantage of the REBP. This strongly suggests that the REBP entitlement strongly drives the pattern of permanent labor force exit. For female workers, the pattern is similar and the size of the first-stage effect is even more pronounced (see Panel (b)).

Column (3) of Table 4 reports the estimates from Panel (a) of Figure 3. The first stage effect ranges from 0.031 years (birth cohort 1931h1) to 1.36 years (birth cohort 1937h2). Beginning with birth cohort 1931h2, all estimates are statistically significant at the 1\%-level (except for birth cohort 1933h2, which is only marginally significant at the 10\%-level). Statistical significance is also reflected in the relevant F statistic, calculated for the excluded instruments only and reported at the bottom of the table. It amounts to 12, i.e. it is larger than the threshold value of 10 above which 2SLS is not supposed to be subject to a weak instruments critique as proposed by Staiger and Stock (1997). Adding further controls again reduces the magnitude of 
the first-stage effect somewhat, but the F statistic for the excluded instruments is still slightly larger than $10 .{ }^{23}$

Column (3) of Table 5 shows the corresponding point estimates for women, displayed graphically in Panel (b) of Figure 3. The first-stage effect varies across birth cohorts, ranging from about 0.33 years (birth cohort 1935h1) to about 1.63 years (birth cohort 1939h2). Starting with birth cohort 1936h1, all coefficients are statistically significant at the 1\%-level. Adding further controls in column (4) hardly changes anything. The F statistic for the excluded instruments exceeds the value of 10 in both column (3) and column (4). This again suggests that we do not run into any weak-instruments issues.

\subsection{Treatment Intensity}

Figure 4 takes a closer look at the distribution of the effective age at retirement by eligibility status, for men and women separately. More precisely, the figure shows the difference in the survivor function of still being in employment at a given age between individuals from eligible versus non-eligible regions. The difference measured on the vertical axis of the figure is negative throughout, indicating that the fraction of workers still at work at any particular age is lower in eligible regions than in non-eligible regions.

Figure 4 about here

We showed above that the individuals retiring between age 55 and 59 are those who drive these effects. This exactly is what we expect from the institutional rules: workers eligible to extended unemployment benefits due to the REBP can already retire at age 55, draw regular unemployment benefits until the age of 59, and then draw benefits from special income support before they become eligible to regular early retirement benefits at the age of 60 . Workers in noneligible regions have no access to extended unemployment benefits and can first claim special income support at age 59. Male blue collar workers eligible to the REBP are 9-14\% less likely to be in employment within the age bracket 55-59. As a consequence, our IV estimates capture

\footnotetext{
${ }^{23}$ Table A.1 in the appendix provides evidence on whether the REBP really causes the contrast in the retirement age, or whether this is simply due to regional differences between eligible and non-eligible districts. It shows the first-stage for cohorts who are not eligible to the REBP (i.e. workers aged less than 50 when the REBP ends). It turns out that no systematic difference emerges between eligible and non-eligible districts for cohorts too young for extended UB entitlement. This strengthens our claim that the contrast in the effective retirement age is causally linked to the REBP.
} 
the causal effect of changes in the retirement age within this age bracket, but tell us little, if anything, about the effects of retiring between the statutory early retirement age (60/55) and the statutory retirement age $(65 / 60)$, for example. ${ }^{24}$

\subsection{The Effect of Early Retirement on Mortality}

Tables 6 and 7 report our main results for blue collar males and females, respectively. Column (1) of Table 6 shows the OLS estimates of a regression of the number of early retirement years on mortality for blue-collar males. The regression controls for birth-cohort fixed-effects, work experience, and NUTS-3 fixed-effects. The OLS estimate is highly significant and amounts to 0.0322 (with a standard error of about 0.0011 ). Taken literally, this would imply that the probability of dying before age 67 increases by 3.22 percentage points for each year of early retirement. In terms of the average probability of dying before age 67 (equal to about 18.0\%), this corresponds to a relative increase of about $17.9 \%$. The inclusion of additional controls does not change the OLS estimate. However, as argued before, OLS estimates are likely plagued by endogeneity bias due to non-random selection into early retirement.

Table 6 about here

Columns (3) to (6) show our 2SLS results. In the just-identified case (i.e. columns (3) and (4)), we get a much smaller point estimate than the corresponding OLS estimate. Using the minimal (extended) set of control variables yields an IV estimate of 0.0078 (0.0122) compared to the corresponding OLS estimate of 0.0322 (0.0324). Moreover, the IV estimate turns out to be statistically insignificant in both cases. In the over-identified case shown in column (5), we get a point estimate of about 0.016 (standard error of 0.0078 ), a decrease in magnitude of about $50 \%$ compared to the corresponding OLS estimate. Even though the standard error of

\footnotetext{
${ }^{24}$ Early retirement also involves a substitution among different labor market activities. Figure A.1 in the appendix shows how eligible and non-eligible workers differ with respect to labor market activities. The lefthand panel shows that workers eligible to the REBP spend less time in employment at ages 50-65 than noneligible workers. If eligibility to extended unemployment benefits drives earlier effective retirement of blue collar workers in eligible regions, we should see more workers on unemployment benefits after permanent exit from employment. This is exactly what we find: eligible workers spend more than 2 percentage points more of their time on unemployment benefits than non-eligible workers. Apparently, the instrument induces individuals to retire earlier by means of the extended unemployment as a channel from work to retirement by first claiming extended unemployment benefits before accessing regular retirement benefits. The right-hand panel shows that eligible workers substitute regular old-age pension with unemployment benefits after they permanently drop out of employment. The figure also shows that time spent out of the labor force does not substantially differ across the two groups (at least for men). In sum, this strongly suggests a pattern of labor market behavior that is consistent with the incentives generated by the REBP.
} 
this estimate is much larger than that in the corresponding OLS regression, the effect remains statistically different from zero at the 5\%-level. Adding further controls in column (6) leads to an even larger point estimate of 0.0242 . This estimate is slightly larger than that from column (3), but it is still about a quarter smaller than the OLS estimate. The estimated standard error is 0.0086 , resulting in statistical significance at the 1\%-level. Based on the 2SLS estimate in column (5) and (6), respectively, one additional year spent in early retirement increases the risk of dying before age 67 by $0.0162(0.0242)$ percentage points. Evaluated at the sample mean of the dependent variable (equal to 0.18), this means a relative increase in the risk of premature death of about $9 \%(13.4 \%)$. Moreover, the comparison between OLS and 2SLS estimates clearly shows that the OLS estimates are contaminated by reverse causality and tend to be too big, which implies that there is selection into early retirement based on ill health. We chose column (6) of Table 6 as our preferred estimate and refer to it as such in the following.

Furthermore, as proposed by Angrist and Pischke (2009), we compare the 2SLS estimates with those produced by the limited information maximum likelihood (LIML) estimator in the over-identified case. ${ }^{25}$ Column (7) corresponds to column (5) except for the fact that the parameters are estimated by LIML rather than 2SLS. LIML estimation yields a point estimate of 0.0144 (standard error of 0.0086). Analogously, column (8) is the LIML estimate that corresponds to the 2SLS estimate shown in column (6). Here we get an estimate of 0.0231 (standard error of 0.0096). In both cases, the LIML estimates are very similar to the 2SLS estimates (though, as expected, less precise than 2SLS). However, both are still statistically significant at least at the 10\%-level. Overall, the comparison between 2SLS and LIML estimates does not suggest that finite-sample bias is a problem (this is not a surprise taking into account that this estimate is based on 17,590 observations).

Our IV-estimates suggest that early exit from the labor force strongly increases mortality. ${ }^{26}$ Our preferred estimate of 0.0242 implies that one additional year of early retirement increases the probability of dying before age 67 by as much as 2.4 percentage points. Evaluated at

\footnotetext{
${ }^{25}$ The more instruments there are, the more relevant issues with weak instruments eventually become. LIML is less biased than 2SLS in finite samples with many instruments, but also has a higher variance.

${ }^{26}$ One might argue that our estimates are be driven by individuals dying while still working, a situation that is in principle possible. Indeed, this may bias our results if death at work occurs with different probability in eligible versus non-eligible districts. To investigate this issue in more detail, we constructed a subsample in which all workers are excluded who die within three months after leaving employment (about 270 male individuals) and then re-estimated our main models. The results remain quantitatively very similar to those presented in Table 6 (results are available upon request).
} 
the average probability of dying before the age of 67 (which is equal to 18.0 percent), this corresponds to a relative increase of about $13.4 \%$.

Table 7 about here

Table 7 shows the corresponding results for female blue-collar workers. The first two columns again report OLS results first. Female workers have a probability of dying before the age of 67 that is increased by about $0.81-0.85$ percentage points for each year spent in early retirement. The magnitude of this conditional correlation is roughly a third smaller than the corresponding effect found for their male counterparts, but this is still a non-negligible correlation (in relative terms this is an effect of $11.8 \%$, a magnitude comparable to their male counterparts). However, and in contrast to our results for men, this effect vanishes completely once we apply the 2SLS estimation (see columns (3) and (5)). The 2SLS estimates tell us that female workers' earlier exit from the work force has no impact on mortality. Again, the corresponding LIML estimates do not indicate that the 2SLS estimates in columns (5) and (6) suffer from small sample bias since LIML yields estimates very close in magnitude to 2SLS coefficients.

Figure 5 about here

Our IV strategy in the over-identified case lends itself to a simple graphical representation, which is given by Figure 5. The visualization builds on the equivalence of 2SLS using a set of dummy instruments and GLS on grouped data, where the grouping is done over the dummy instruments (this equivalence is elaborated in Angrist, 1991). Briefly, the left-hand panel of Figure 5 shows the relationship between the probability of being eligible to the REBP on the horizontal axis and the probability of dying before age 67 on the vertical axis (which in turn may be understood as a plot of the reduced form against the first-stage). The figure plots average residuals by year-semester date of birth and eligibility status from a regression of the dependent variable (the endogenous variable, respectively) on cohort fixed-effects, NUTS-3 fixed effects, and controls for past work experience (using corresponding cell sizes as weights). The right-hand panel of Figure 5 shows average residuals from regressions that include additional control variables (corresponding to regression specification shown in column (6) in Table 6). The figure clearly shows that there is a positive causal relation between the number of early retirement years and the probability of premature death (before age 67) for male workers. In contrast, Panel (b) of Figure 5 shows that no such relation exists for female workers. 


\section{$6 \quad$ Why Is There Excess Mortality Among Males?}

The above analysis has documented a negative and sizable effect of early exit from working life on mortality for male blue-collar workers but not for female counterparts. We now try to shed light on several specific channels that might help explain the observed increased mortality among male early retirees.

We first show that losses in earnings associated with early retirement are quite small and thus cannot be the main explanation of the evident excess mortality among male workers. Second, we use ancillary information to study differences in death causes and hospital admission of male workers residing in eligible and non-eligible districts. Third, we provide some suggestive evidence on the impact of retirement voluntariness on the estimated effect of early retirement on premature death. As the preceding section has shown no causal effect of early retirement on premature death for women, we focus on male retirees only in this section.

\subsection{Earnings Losses}

Earnings losses may contribute to an explanation of excess mortality among early retirees. To check the relevance of this channel, we first have to estimate the reduction in permanent earnings for individuals aged 50 or older if they retire one year earlier. We find that the reduction in permanent income for individuals aged 50 or older is only about 2.5 percent. ${ }^{27}$ Taken at face value, the estimated OLS estimate of -0.10 for the effect of average earnings before the age of 50 on mortality would imply that we expect an increase in the probability of dying before age 67 of about 0.25 percentage points. ${ }^{28}$ We therefore conclude that at most $10 \%$ of our preferred estimate of the causal effect of retirement on premature mortality can be explained by the reduction in permanent income associated with early retirement. ${ }^{29}$

The income channel in our case is much less important than that in a recent study by Sullivan and Wachter (2009), who find that this specific channel accounts for as much as $50 \%-75 \%$ of the overall effect of involuntary job loss on mortality in the US. The fact that there is compulsory

\footnotetext{
${ }^{27}$ See Table A.2 in the appendix. Note further that the volatility of income is a minor issue only in our context because income streams are constant as soon as an individual draws pension benefits.

${ }^{28}$ The OLS estimate is taken from column (2) of Table 6. Based on this estimate, a reduction in permanent income of $2.5 \%$ implies an increase in the probability of death before age 67 of approximately $-(-0.010 / 100)$. $0.025=0.0025$. This figure is likely to overestimate the effect of earnings on mortality because the OLS estimate of the effect of earnings on premature death is arguably biased upward.

${ }^{29}$ This number results from dividing the estimated effect of the reduction in permanent income of 0.0025 by our preferred 2SLS estimate of 0.0242, taken from column (6) of Table 6.
} 
and universal health insurance coverage in Austria reconciles this difference, however. Moreover, the reduction in income after retiring early is mitigated by relatively high income replacement rates in the Austrian pension system. In sum, we conclude that earnings losses associated with early retirement are too small to provide a credible explanation for our finding of excess mortality among males.

\subsection{Health-Related Behavior}

Another likely channel is that early retirees change their health-related behavior. We shed light on this potential explanation by looking at how cause-specific mortality and diagnoses leading to hospital admissions differ between eligible and non-eligible individuals. We can do so using two independent data sources on cause-specific mortality and main diagnosis for admissions into hospital, respectively.

\section{Cause-Specific Mortality}

Cause-specific mortality rates are interesting in the present context because they can be related to changes in health-related behaviors. We now additionally rely on official statistics of death causes provided by Statistics Austria. The data contain information about detailed causes of death according to the 10th revision of the International Classification of Diseases and Related Health Problems (ICD-10).

We restrict our initial sample of 17,950 male blue collar workers to those workers who died before December 2008, which leaves us with 5,737 observations. ${ }^{30}$ While information on causes of death from Statistics Austria cannot be linked directly with the ASSD it turns out that we are able to match information from both data sources for 4,341 observations (roughly $76 \%$ of the overall sample) using a very simple algorithm. ${ }^{31}$ Finally, we focus on those 3,967 individuals whom we could match uniquely. Overall, the following analysis is thus based on about $69 \%$ of all male workers who died before December 2008.

\section{Table 8 about here}

\footnotetext{
${ }^{30}$ In comparison, there are only 3,172 deaths underlying our main results. The difference stems from the fact that we only look at deaths occurring between age 50 and 67 in our main analysis, while we include all deaths before December 2008 in the analysis of cause-specific mortality, which also includes deaths that occur after age 67.

${ }^{31}$ The matching procedure is based on the following four characteristics: year and month of birth, year and month of death, NUTS-3 unit, and eligible/non-eligible district.
} 
In Table 8 we look at the following causes of death: mental health, self-inflicted injuries, external injuries, cardiovascular diseases, cerebrovascular diseases, cancer, and respiratory disorders. $^{32}$ The top row of Table 8 clearly shows that cancer and cardiovascular causes account for the majority of deaths (about 65\%) observed in this sample.

Panel (a) of Table 8 shows reduced form estimates of dummy variables indicating several distinct causes of death on our instrument denoting residency within an eligible district (and the same additional controls that we used earlier). We do not find any statistically significant effect, except for cardiovascular causes (see column (4)). Moreover, the corresponding point estimate implies a large relative difference in the incidence of deaths related to cardiovascular disorders between eligible and non-eligible individuals of almost $10 \%(=0.0275 / 0.2796)$. Corresponding 2SLS estimates (shown in panel (b) of Table 8) corroborate this finding. ${ }^{33}$ The 2SLS estimate of the instrument on the probability of dying due to some cardiovascular disorder is 0.045 (standard error of 0.026 ), and thus about 1.63 times larger than the corresponding reduced form effect.

We believe that this intriguing result points to changes in retirees' behavior as a potentially important explanation for the excess mortality of male blue-collar early retirees. Indeed, there is a broad consensus in the medical literature that there are only a few main risk factors associated with cardiovascular infarction and coronary heart disease. Among the most important risk factors are smoking, hypertension, diabetes, obesity, and psychosocial factors, while a healthy diet (i.e. fruit and vegetables) and regular physical exercise appear to be protective (Canto and Iskandrian, 2003; Greenland et al., 2003; Yusuf et al., 2004). Note that some of these main risk factors are directly associated with daily lifestyle and can thus be directly influenced by individuals' behavior: smoking, diet, and physical exercise. Notably, smoking is consistently shown to be the single most important risk factor of coronary heart disease. We therefore infer from the results from Table 8 that changes in health-related behaviors, especially smoking, are an important explanatory factor for excess mortality among male retirees. ${ }^{34}$

\footnotetext{
${ }^{32}$ The major causes of death contain the following ICD-10 codes. Mental health: F00-F99. Self-inflicted injuries: X60-X84. Other external causes: X1-X59, X85-X99, Y10-Y34. Cardiovascular disorders: I1-I52. Cerebrovascular disorders: I60-I69. Cancer: C00-C97, D00-D48. Respiratory disorders: J00-J99.

${ }^{33}$ Table A.3 in the appendix shows even somewhat larger effects when we include additional control variables.

${ }^{34}$ See also Bedard and Deschênes (2006) who argue that smoking drives most of the observed excess mortality among World War II and Korean War Veterans in the U.S..
} 


\section{Hospital Admissions}

To corroborate this explanation based on changes in behavior we present additional evidence based on an ancillary, but otherwise independent data source. These additional data is from the public health insurance fund of the state of Upper Austria ("Oberösterreich") and covers the period from January 1, 1998 until December 31, 2002. Basic health insurance is mandatory in Austria and administered by the states. As a consequence, all individuals from Upper Austria who are registered in the ASSD are also covered in the public health insurance data of Upper Austria. Luckily, the state of Upper Austria covers both eligible and non-eligible districts ${ }^{35}$. The health insurance data can be directly matched to the ASSD via a common (anonymized) social security identifier.

The data from the health insurance fund report all payments the public insurance fund makes for health-related treatments of insured individuals. Hence the data contain very detailed information. Specifically, we can observe detailed causes for hospital admissions based on the 9th revision of the International Classification of Diseases and Related Health Problems (ICD-9). The specific information we use is the main medical diagnosis which led to an individual's admission into hospital. In the following, we look at those workers who are principally covered by the health insurance fund and who died in the time window available in the health insurance data. ${ }^{36}$ More specifically, we look at differences in main diagnosis for hospital admissions between eligible and non-eligible workers (in the same way that we looked at differences in cause-specific mortality in Table 8). Table 9 shows both reduced form and 2SLS estimates for the probability of several main diagnoses of hospital admission. ${ }^{37}$

Table 9 about here

Panel (a) of Table 9 shows reduced form estimates from a simple binary indicator (denot-

\footnotetext{
${ }^{35}$ Upper Austria covers about a sixth of the overall Austrian workforce and is located in the northern part of Austria, bordering both Germany and the Czech Republic. The two NUTS-3 units "Innviertel" and "SteyrKirchdorf" are part of Upper Austria. Together, these districts comprise about $30 \%$ of our male sample (see bottom of Table 1).

${ }^{36}$ Of the overall sample of 17,590 male workers, 5,075 are in principle covered by the health insurance data (about 29\%), and 523 individuals died between January 1998 and December 2002. Moreover, at least one hospital admission is registered for 430 of these 523 individuals. We use this subset of individuals because the cause for admission to hospital is arguably closely linked to the cause of death for this subset of individuals.

${ }^{37}$ The different categories of cause for hospital admission contain the following ICD-9 codes. Mental health: 290319, V70.1, V70.2, and V71.0. Cardiovascular disorders: 391-398, 402, 404, 410-429. Cerebrovascular disorders: 430-438. Cancer: 140-239. Respiratory disorders: 460-519. Table A.4 in the appendix gives analogous results when additional controls are included in the statistical model.
} 
ing main cause of hospital admission) on our dummy instrument conditional on age, previous employment, and place of work. Point estimates of substantial size result in the case of heart disease and respiratory disorders (positive coefficients). Unfortunately, we cannot reject the null hypothesis of no difference in the probability of being diagnosed with either heart disease or respiratory disorders, which is most likely due to too few observations. In panel (b) of Table 9 we report the corresponding IV estimates. Again, the resulting point estimate is highest in the case of hospital admission due to a cardiovascular disease, albeit it is not statistically significant. Also note that we find a quite large point estimate on respiratory disorders in Table 9, but not in Table 8. While this coefficient is again estimated only imprecisely, it again suggests that smoking in particular could be a key contributor the excess mortality among males.

While the evidence from Table 9 clearly needs to be treated with some caution, we conclude that this evidence is broadly consistent with the evidence from cause-specific mortality, and thus corroborates our hypothesis that changes in lifestyle and health-related behavior are likely channels explaining increased mortality among male retirees.

\subsection{Retirement voluntariness}

Another hypothesis is related to firing decisions of firms. Since the REBP mitigated economic hardships associated with unemployment of older workers, the implementation of this program made it easier for firms to release older workers. If these firm decisions underlie the estimated treatment effects, we should see a larger effect among released workers as opposed those who voluntarily quit their jobs (see Henkens et al., 2008; van Solinge and Henkens, 2007, on retirement voluntariness)..$^{38}$

While it is not possible to directly distinguish between quits and layoffs in our data, we can exploit the institutional particularity that there are sharp discontinuities in eligibility for severance pay in Austria. After 3 years of continuous work history with the same employer, a worker becomes eligible for severance payments. Severance payments amount to twice the monthly salary and increase to three salaries after 5 years, to four after 10 years, to six after 15

\footnotetext{
${ }^{38}$ Of course, there are other potential sources of treatment effect heterogeneity. One especially interesting dimension is workers' ex-ante health status because it is easily imaginable that mortality effects be predominantly driven by workers with weak ex-ante health. Appendix table A.5 sheds light on this issue. The mortality effect is strong and highly significant ex-ante among workers who are unhealthier. This suggests that effective early retirement causes premature death by adding to already existing health problems. In contrast, we see that the mortality effect is small and insignificant among workers who are ex-ante healthier.
} 
years, to nine after 20 years, and to twelve monthly salaries after 25 years of continuous work history with the same employer. Given that the financial stakes involved are quite high, one might argue that a comparison of workers just above and below any given threshold may be informative about the degree of retirement voluntariness. More specifically, it may be reasonable to assume that the probability of a voluntary quit is higher, ceteris paribus, if a worker has just crossed any of the tenure thresholds above, and thus received severance pay, compared to the situation that he just failed to cross the threshold (and thus had to forego [increased] severance pay). Before the threshold around 10, for example, the worker only gets three months of severance pay and might be sorely tempted to wait around to get six. If he goes before ten years, he does not lose severance pay, but receives a reduced amount.

Table 10 about here

Table 10 shows the resulting estimates using two different subsamples. The first (second) subsample contains only male workers with job tenure in a range of up to 6 (12) months around any tenure threshold relevant for severance pay (i.e. $3,5,10,15,20$, or 25 years of job tenure). We then re-estimate, for each of the two subsamples, our main models of columns (5) and (6) of Table 6 for those workers below or above any existing tenure threshold relevant for severance pay. The first four columns show estimates based on the subsample including only workers with job tenure within 6 months of any threshold. The first column shows a significant effect of retirement on premature death for workers below the tenure threshold, while the third column only shows a small, and statistically, insignificant effect for workers just above the tenure threshold. A similar result is obtained if additional controls are used (compare columns (2) and (4)) and if the subsample considered includes workers within 12 months of any tenure threshold (remaining columns of Table 10).

Even though we cannot directly distinguish between voluntary and involuntary entry into early retirement, we find suggestive evidence that retirement voluntariness may indeed be related to the health effects of early retirement and the potentially underlying behavior. Early retirement followed by voluntary quits seem to be unrelated to mortality, while early retirement caused by involuntary layoffs is so. 


\section{Conclusions}

We estimate the causal effect of early retirement on mortality for blue collar workers in this paper. To resolve the reverse causality issue, we exploit a policy change to the Austrian unemployment insurance system which allowed workers in eligible regions to withdraw from the labor market up to 3.5 years earlier than workers in non-eligible regions. The policy was implemented in the late 1980s in response to the international steel crisis and was confined to regions with a strong steel sector. Major labor market problems arose within these regions as a result of this crisis and the policy was intended to mitigate associated economic hardships for older workers. Since the program generated exogenous variation in the effective early-retirement age, we can estimate the causal impact of early retirement on mortality using instrumental variable techniques.

For males, we find that a reduction in the effective retirement age causes a significant increase in the risk of premature death. The effect for males is not only statistically significant but also quantitatively important. Advancing the date of permanent exit from the work force by one year causes an increase in the risk of premature death of 2.4 percentage points (resulting in a large relative increase of about $13.4 \%$ ). We find that lower permanent income after retirement is unlikely to explain higher mortality because earnings losses are too small to cause significant health problems and because access to health care does not depend on employment status. However, results using additional information on cause-specific mortality indicate that the incidence of cardiovascular death causes is substantially larger among early retirees from eligible regions, suggesting that changes in health-related behaviors (e.g. physical activity, drinking, smoking) are the likely cause of higher mortality rates. This finding is corroborated by additional analyses on main diagnoses for hospital admissions. We do not find that earlier effective retirement increases the risk of premature death for females, however. The reason may be that women are more capable of coping with retirement, as work is of lower importance in the traditional gender role model; that they remain more active after retirement due to household activities; or that they are more health-conscious and less likely to adopt unhealthy behaviors.

In line with prior expectations and previous evidence, we also find that IV-estimates are smaller than the simple OLS estimate, both for men and for women. This is consistent with negative health-driven selection into retirement and underlines the importance of a proper iden- 
tification strategy when estimating the causal impact of early retirement on mortality. Finally, we find some evidence in line with the view that involuntary early retirement has a negative impact on health, but not necessarily voluntary early retirement. 


\section{References}

Abadie, A. (2003). Semiparametric instrumental variable estimation of treatment response models. Journal of Econometrics, 113(2), 231 - 263.

Angrist, J. (1991). Grouped-data estimation and testing in simple labor-supply models. Journal of Econometrics, 47(2/3), 243-266.

Angrist, J. (2001). Estimation of Limited Dependent Variable Models with Dummy Endogenous Regressors: Simple Strategies for Empirical Practice. Journal of Business 83 Economic Statistics, 19(1), 2-16.

Angrist, J. and Pischke, J. (2009). Mostly harmless econometrics: an empiricist's companion. Princeton University Press.

Angrist, J., Imbens, G., and Rubin, D. (1996). Identification of causal effects using instrumental variables. Journal of the American Statistical Association, 91(434).

Baker, M., Stabile, M., and Deri, C. (2004). What do self-reported, objective, measures of health measure? Journal of Human Resources, 39(4), 1067.

Balia, S. and Jones, A. (2008). Mortality, lifestyle and socio-economic status. Journal of Health Economics, 27(1), 1-26.

Bamia, C., Trichopoulou, A., and Trichopoulos, D. (2008). Age at retirement and mortality in a general population sample: the Greek EPIC study. American Journal of Epidemiology, 167(5), 561-569.

Bedard, K. and Deschênes, O. (2006). The long-term impact of military service on health: evidence from World War II and Korean War veterans. American Economic Review, 96(1), 176-194.

Behncke, S. (2009). How Does Retirement Affect Health? IZA Discussion Paper No. 4253.

Bound, J. (1991). Self-reported versus objective measures of health in retirement models. Journal of Human Resources, 26(1), 106-138.

Bound, J. and Waidmann, T. (2007). Estimating the Health Effects of Retirement. Working Paper 2007-168, University of Michigan.

Brockmann, H., Müller, R., and Helmert, U. (2009). Time to retire - Time to die? A prospective cohort study of the effects of early retirement on long-term survival. Social Science $\mathbb{E}$ Medicine, 69(2), 160-164.

Canto, J. and Iskandrian, A. (2003). Major risk factors for cardiovascular disease: debunking the "only 50\%" myth. Jama, 290(7), 947.

Charles, K. (2002). Is Retirement Depressing? Labor Force Inactivity and Psychological WellBeing in Later Life. NBER Working Paper No. 9033.

Coe, N. and Zamarro, G. (2008). Retirement Effects on Health in Europe. RAND Working Paper No. 588.

Coe, N. B. and Lindeboom, M. (2008). Does Retirement Kill You? Evidence from Early Retirement Windows. IZA Discussion Paper No. 3817. 
Dave, D., Rashad, I., and Spasojevic, J. (2008). The effects of retirement on physical and mental health outcomes. Southern Economic Journal, 75(2), 497-523.

Disney, R., Emmerson, C., and Wakefield, M. (2006). Ill health and retirement in Britain: A panel data-based analysis. Journal of Health Economics, 25(4), 621-649.

Dwyer, D. and Mitchell, O. (1999). Health problems as determinants of retirement: Are selfrated measures endogenous? Journal of Health Economics, 18(2), 173-193.

Eliason, M. and Storrie, D. (2009). Does Job Loss Shorten Life? Journal of Human Resources, 44(2), 277.

Gallo, W., Teng, H., Falba, T., Kasl, S., Krumholz, H., and Bradley, E. (2006). The impact of late career job loss on myocardial infarction and stroke: a 10 year follow up using the health and retirement survey. British Medical Journal, 63(10), 683.

Greenland, P., Knoll, M., Stamler, J., Neaton, J., Dyer, A., Garside, D., and Wilson, P. (2003). Major risk factors as antecedents of fatal and nonfatal coronary heart disease events. Jama, 290(7), 891.

Henkens, K., Van Solinge, H., and Gallo, W. (2008). Effects of retirement voluntariness on changes in smoking, drinking and physical activity among Dutch older workers. European Journal of Public Health, 18(6), 644.

Hofer, H. and Koman, R. (2006). Social security and retirement incentives in Austria. Empirica, 33(5), 285-313.

Imbens, G. and Angrist, J. (1994). Identification and estimation of local average treatment effects. Econometrica, 62(2), 467-475.

Johnston, D. and Lee, W. (2009). Retiring to the good life? The short-term effects of retirement on health. Economics Letters, 103(1), 8-11.

Kerkhofs, M. and Lindeboom, M. (1997). Age related health dynamics and changes in labour market status. Health Economics, 6(4), 407-423.

Koch, M. and Thimann, C. (1999). From generosity to sustainability: The Austrian pension system and options for its reform. Empirica, 26(1), 21-38.

Lalive, R. (2008). How do extended benefits affect unemployment duration? A regression discontinuity approach. Journal of Econometrics, 142(2), 785-806.

Lalive, R. and Zweimüller, J. (2004a). Benefit Entitlement and the Labor Market: Evidence from a Large-Scale Policy Change. In J. Agell, M. Keen, and A. J. Weichenrieder, editors, Labor Market Institutions and Public Regulation, pages 63-100. MIT Press.

Lalive, R. and Zweimüller, J. (2004b). Benefit entitlement and unemployment duration. The role of policy endogeneity. Journal of Public Economics, 88(12), 2587-2616.

Litwin, H. (2007). Does early retirement lead to longer life? Ageing and Society, 27(05), $739-754$.

Midanik, L., Soghikian, K., Ransom, L., and Tekawa, I. (1995). The effect of retirement on mental health and health behaviors: the Kaiser Permanente Retirement Study. Journals of Gerontology Series B: Psychological Sciences and Social Sciences, 50, 59-59. 
Morris, J., Cook, D., and Shaper, A. (1994). Loss of employment and mortality. British medical journal, 308(6937), 1135-1139.

Neuman, K. (2008). Quit Your Job and Get Healthier? The Effect of Retirement on Health. Journal of Labor Research, 29(2), 177-201.

OECD (2004). Employment Outlook. Technical report, Organisation for Economic Co-operation and Development.

OECD (2007). Pensions at a Glance. Technical report, Organisation for Economic Co-operation and Development.

Rege, M., Telle, K., and Votruba, M. (2009). The effect of plant downsizing on disability pension utilization. Journal of the European Economic Association, 7(4), 754-785.

Rohwedder, S. and Willis, R. J. (2010). Mental retirement. Journal of Economic Perspectives, 24(1), 119-138.

Scarmeas, N. and Stern, Y. (2003). Cognitive reserve and lifestyle. Journal of Clinical and Experimental Neuropsychology, 25(5), 625-633.

Staiger, D. and Stock, J. (1997). Instrumental variables regression with weak instruments. Econometrica, 65(3), 557-586.

Sullivan, D. and Wachter, T. (2009). Job Displacement and Mortality: An Analysis Using Administrative Data. Quarterly Journal of Economics, 124(3), 1265-1306.

Tsai, S., Wendt, J., Donnelly, R., de Jong, G., and Ahmed, F. (2005). Age at retirement and long term survival of an industrial population: prospective cohort study. British Medical Journal, 331(7523), 995.

van Solinge, H. and Henkens, K. (2007). Involuntary retirement: The role of restrictive circumstances, timing, and social embeddedness. Journals of Gerontology Series B: Psychological Sciences and Social Sciences, 62(5), S295.

Winter-Ebmer, R. (1998). Potential unemployment benefit duration and spell length: lessons from a quasi-experiment in Austria. Oxford Bulletin of Economics and Statistics, 60(1), $33-45$.

Winter-Ebmer, R. (2001). Evaluating an Innovative Redundancy-Retraining Project: The Austrian Steel Foundation. IZA Discussion Paper No. 277.

Yusuf, S., Hawken, S., Ôunpuu, S., Dans, T., Avezum, A., Lanas, F., McQueen, M., Budaj, A., Pais, P., Varigos, J., et al. (2004). Effect of potentially modifiable risk factors associated with myocardial infarction in 52 countries (the INTERHEART study): case-control study. The Lancet, 364(9438), 937-952.

Zweimüller, J., Winter-Ebmer, R., Lalive, R., Kuhn, A., Ruf, O., Wuellrich, J.-P., and Büchi, S. (2009). The Austrian Social Security Database (ASSD). IEW Working Paper No 410. 


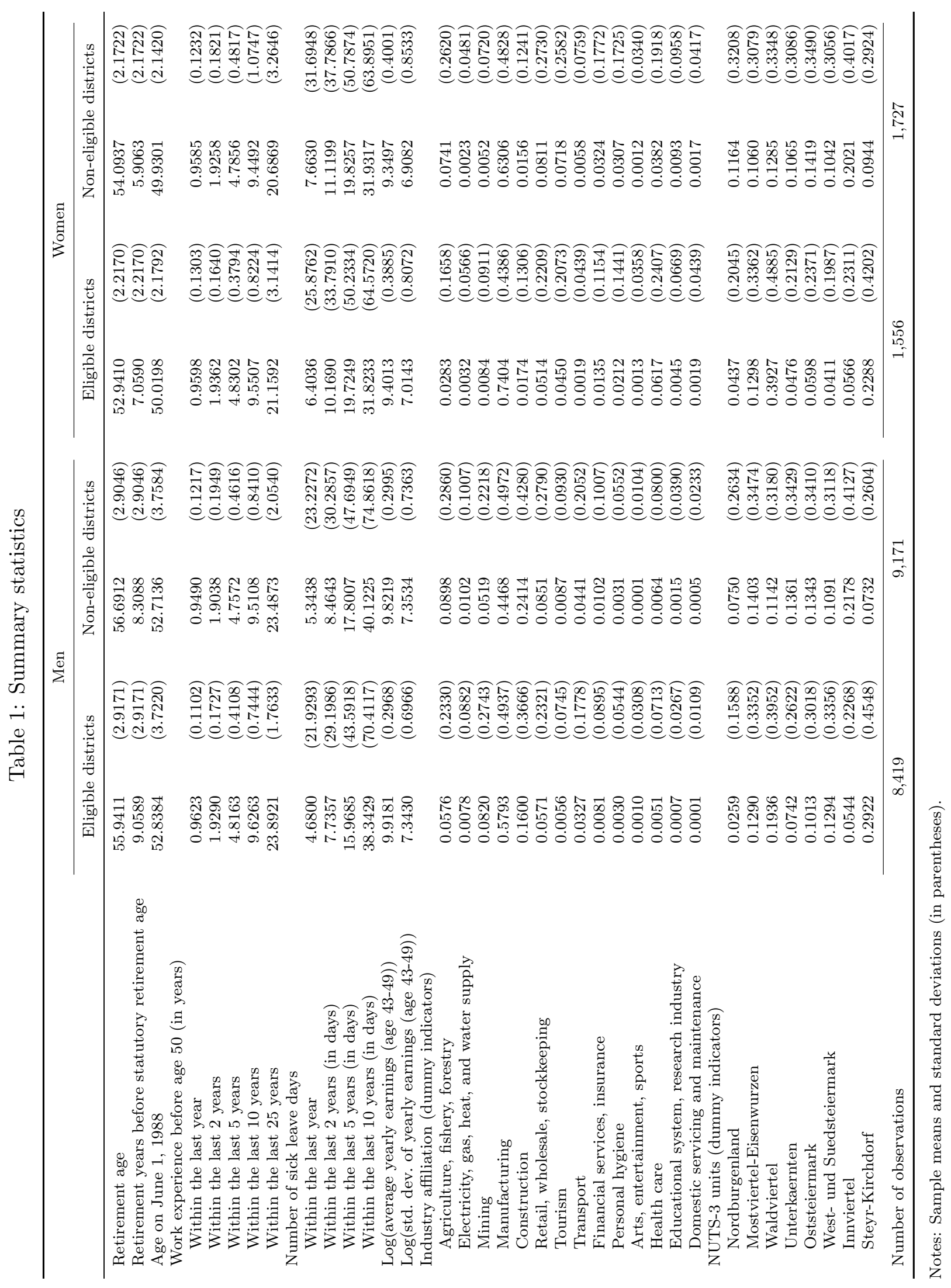




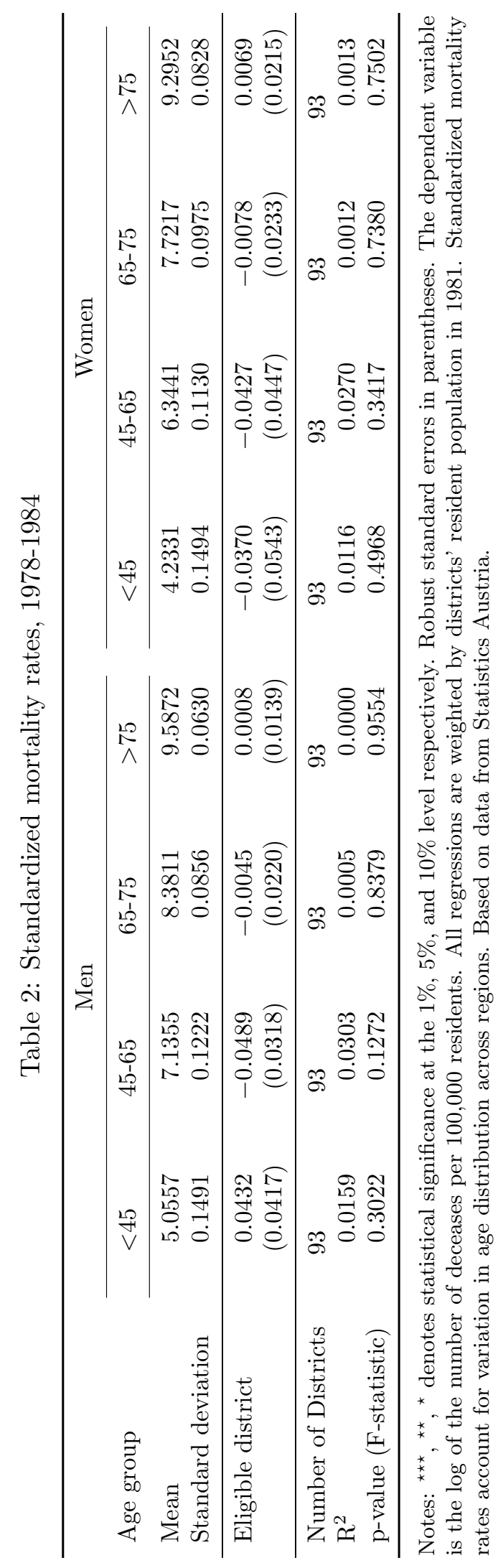




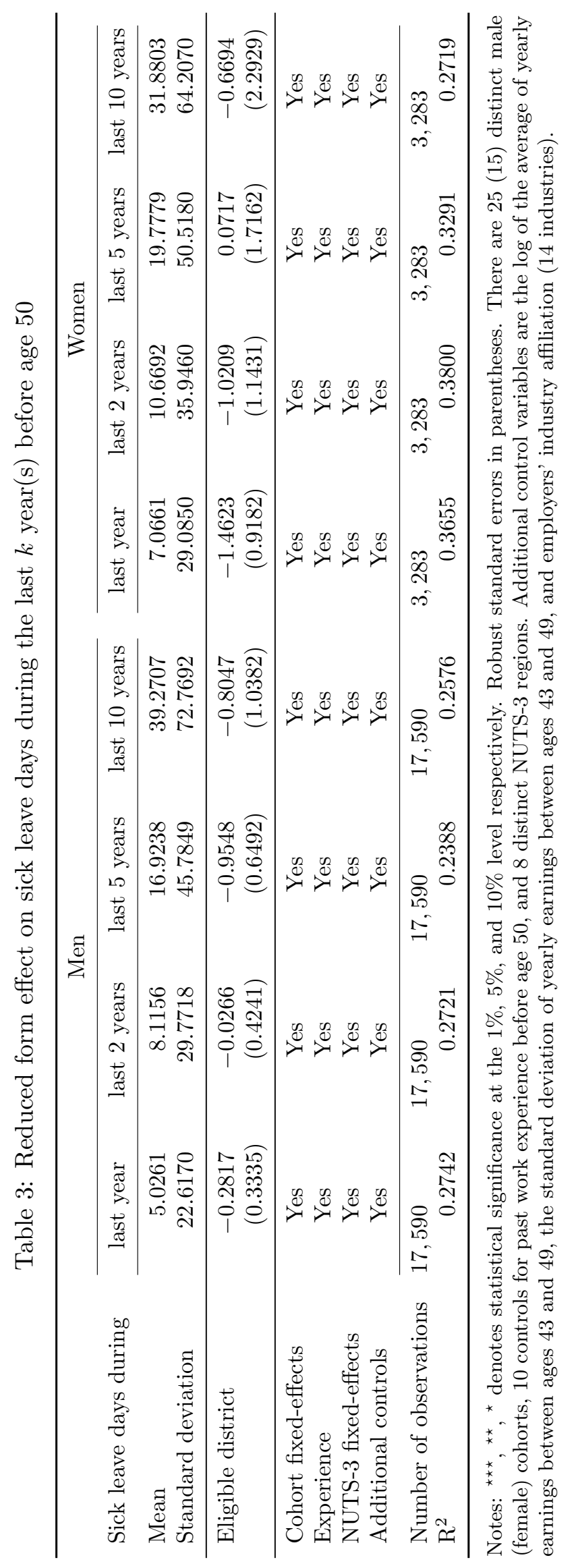


Table 4: First-stage results, men

\begin{tabular}{|c|c|c|c|c|}
\hline \multirow{3}{*}{$\begin{array}{l}\text { Mean } \\
\text { Standard deviation }\end{array}$} & \multicolumn{4}{|c|}{ Retirement years before the statutory retirement age } \\
\hline & 8.6678 & 8.6678 & 8.6678 & 8.6678 \\
\hline & 2.9346 & 2.9346 & 2.9346 & 2.9346 \\
\hline Eligible district & $0.7100^{\star \star \star}$ & $0.5895^{\star \star \star}$ & & \\
\hline Eligible district $\cdot 1929 \mathrm{~h} 2$ & & & $0.3652^{\star \star}$ & 0.0900 \\
\hline Eligible district $\cdot 1930 \mathrm{~h} 1$ & & & 0.1658 & -0.0254 \\
\hline Eligible district $\cdot 1930 \mathrm{~h} 2$ & & & 0.0879 & -0.1167 \\
\hline Eligible district · $1931 \mathrm{~h} 1$ & & & 0.0307 & -0.0617 \\
\hline Eligible district $\cdot 1931 \mathrm{~h} 2$ & & & $0.7390^{\star \star \star}$ & $0.5466^{\star \star \star}$ \\
\hline Eligible district · $1932 \mathrm{~h} 1$ & & & $0.6021^{\star \star \star}$ & $0.4285^{\star \star}$ \\
\hline Eligible district $\cdot 1932 \mathrm{~h} 2$ & & & $0.8066^{\star \star \star}$ & $0.6584^{\star \star \star}$ \\
\hline Eligible district $\cdot 1933 \mathrm{~h} 1$ & & & $0.6284^{\star \star \star}$ & $0.4503^{\star \star}$ \\
\hline Eligible district $\cdot 1933 \mathrm{~h} 2$ & & & $0.3868^{\star}$ & 0.2533 \\
\hline Eligible district · $1934 \mathrm{~h} 1$ & & & $0.6323^{\star \star \star}$ & $0.4812^{\star \star}$ \\
\hline Eligible district $\cdot 1934 \mathrm{~h} 2$ & & & $0.9923^{\star \star \star}$ & $0.8322^{\star \star \star}$ \\
\hline Eligible district $\cdot 1935 \mathrm{~h} 1$ & & & $0.9849^{\star \star \star}$ & $0.7802^{\star \star \star}$ \\
\hline Eligible district $\cdot 1935 \mathrm{~h} 2$ & & & $0.7494^{\star \star \star}$ & $0.5207^{\star \star}$ \\
\hline Eligible district $\cdot 1936 \mathrm{~h} 1$ & & & $1.2162^{\star \star \star}$ & $1.1637^{\star \star \star}$ \\
\hline Eligible district $\cdot 1936 \mathrm{~h} 2$ & & & $0.6622^{\star \star \star}$ & $0.6336^{\star \star \star}$ \\
\hline Eligible district $\cdot 1937 \mathrm{~h} 1$ & & & $1.0500^{\star \star \star}$ & $1.0469^{\star \star \star}$ \\
\hline Eligible district $\cdot 1937 \mathrm{~h} 2$ & & & $1.3570^{\star \star \star}$ & $1.2406^{\star \star \star}$ \\
\hline Eligible district $\cdot 1938 \mathrm{~h} 1$ & & & $0.9968^{\star \star \star}$ & $0.9708^{\star \star \star}$ \\
\hline Eligible district $\cdot 1938 \mathrm{~h} 2$ & & & $0.5397^{\star \star}$ & 0.3333 \\
\hline Eligible district $\cdot 1939 \mathrm{~h} 1$ & & & $1.1068^{\star \star \star}$ & $0.9968^{\star \star \star}$ \\
\hline Eligible district $\cdot 1939 \mathrm{~h} 2$ & & & $0.7041^{\star \star \star}$ & $0.5939^{\star \star \star}$ \\
\hline Eligible district $\cdot 1940 \mathrm{~h} 1$ & & & $0.8803^{\star \star \star}$ & $0.9863^{\star \star \star}$ \\
\hline Eligible district $\cdot 1940 \mathrm{~h} 2$ & & & $0.9150^{\star \star \star}$ & $0.8897^{\star \star \star}$ \\
\hline Eligible district $\cdot 1941 \mathrm{~h} 1$ & & & $0.9651^{\star \star \star}$ & $0.9921^{\star \star \star}$ \\
\hline Eligible district $\cdot 1941 \mathrm{~h} 2$ & & & $0.6944^{\star \star \star}$ & $0.5212^{\star \star}$ \\
\hline Cohort fixed-effects & Yes & Yes & Yes & Yes \\
\hline Experience & Yes & Yes & Yes & Yes \\
\hline NUTS fixed-effects & Yes & Yes & Yes & Yes \\
\hline Additional controls & No & Yes & No & Yes \\
\hline Number of observations & 17,590 & 17,590 & 17,590 & 17,590 \\
\hline $\mathrm{R}^{2}$ & 0.1326 & 0.1980 & 0.1357 & 0.2021 \\
\hline First Stage F-statistic (Instruments) & 243.0828 & 174.5787 & 11.9630 & 10.2984 \\
\hline
\end{tabular}

Notes: ${ }^{\star \star \star},{ }^{\star \star},{ }^{\star}$ denotes statistical significance at the $1 \%, 5 \%$, and $10 \%$ level respectively. Robust standard errors in parentheses. There are 25 (15) distinct male (female) cohorts, 10 controls for past work experience before age 50, and 8 distinct NUTS-3 regions. Additional control variables are the log of the average of yearly earnings between ages 43 and 49 , the standard deviation of yearly earnings between ages 43 and 49, the number of sick-leave days before age 50 (10 terms), and employers' industry affiliation (14 industries). 
Table 5: First stage effect, women

\begin{tabular}{|c|c|c|c|c|}
\hline \multirow{3}{*}{$\begin{array}{l}\text { Mean } \\
\text { Standard deviation }\end{array}$} & \multicolumn{4}{|c|}{ Retirement years before the statutory retirement age } \\
\hline & 6.4526 & 6.4526 & 6.4526 & 6.4526 \\
\hline & 2.2675 & 2.2675 & 2.2675 & 2.2675 \\
\hline Eligible district & $1.0104^{\star \star \star}$ & $0.9399^{\star \star \star}$ & & \\
\hline Eligible district $\cdot 1934 \mathrm{~h} 2$ & & & $0.6717^{\star \star}$ & $0.5006^{\star}$ \\
\hline Eligible district $\cdot 1935 \mathrm{~h} 1$ & & & 0.3345 & 0.3267 \\
\hline Eligible district $\cdot 1935 \mathrm{~h} 2$ & & & 0.4140 & 0.2519 \\
\hline Eligible district $\cdot 1936 \mathrm{~h} 1$ & & & $0.7349^{\star \star}$ & $0.4873^{\star}$ \\
\hline Eligible district $\cdot 1936 \mathrm{~h} 2$ & & & $0.7092^{\star \star}$ & $0.6789^{\star \star}$ \\
\hline Eligible district $\cdot 1937 \mathrm{~h} 1$ & & & $1.1734^{\star \star \star}$ & $0.9597^{\star \star \star}$ \\
\hline Eligible district $\cdot 1937 \mathrm{~h} 2$ & & & $1.2091^{\star \star \star}$ & $1.0138^{\star \star \star}$ \\
\hline Eligible district $\cdot 1938 \mathrm{~h} 1$ & & & $1.1244^{\star \star \star}$ & $0.9275^{\star \star \star}$ \\
\hline Eligible district $\cdot 1938 \mathrm{~h} 2$ & & & $0.9883^{\star \star \star}$ & $1.1578^{\star \star \star}$ \\
\hline Eligible district $\cdot 1939 \mathrm{~h} 1$ & & & $0.8349^{\star \star \star}$ & $0.8560^{\star \star \star}$ \\
\hline Eligible district $\cdot 1939 \mathrm{~h} 2$ & & & $1.6288^{\star \star \star}$ & $1.6173^{\star \star \star}$ \\
\hline Eligible district $\cdot 1940 \mathrm{~h} 1$ & & & $1.1276^{\star \star \star}$ & $1.1186^{\star \star \star}$ \\
\hline Eligible district $\cdot 1940 \mathrm{~h} 2$ & & & $1.3271^{\star \star \star}$ & $1.2925^{\star \star \star}$ \\
\hline Eligible district $\cdot 1941 \mathrm{~h} 1$ & & & $1.2916^{\star \star \star}$ & $1.3071^{\star \star \star}$ \\
\hline Eligible district $\cdot 1941 \mathrm{~h} 2$ & & & $1.1064^{\star \star \star}$ & $1.0060^{\star \star \star}$ \\
\hline Cohort fixed-effects & Yes & Yes & Yes & Yes \\
\hline Experience & Yes & Yes & Yes & Yes \\
\hline NUTS fixed-effects & Yes & Yes & Yes & Yes \\
\hline Additional controls & No & Yes & No & Yes \\
\hline Number of observations & 3,283 & 3,283 & 3,283 & 3,283 \\
\hline $\mathrm{R}^{2}$ & 0.1721 & 0.2489 & 0.1779 & 0.2558 \\
\hline First Stage F-statistic (Instruments) & 153.1078 & 137.4533 & 11.9306 & 11.2351 \\
\hline
\end{tabular}

Notes: ${ }^{\star \star \star},{ }^{\star \star},{ }^{\star}$ denotes significance at the $1 \%, 5 \%$, and $10 \%$ level respectively. Robust standard errors in parentheses. There are 25 (15) distinct male (female) cohorts, 10 controls for past work experience before age 50, and 8 distinct NUTS-3 regions. Additional control variables are the log of the average of yearly earnings between ages 43 and 49, the standard deviation of yearly earnings between ages 43 and 49 , the number of sick-leave days before age 50 (10 terms), and employers' industry affiliation (14 industries). 


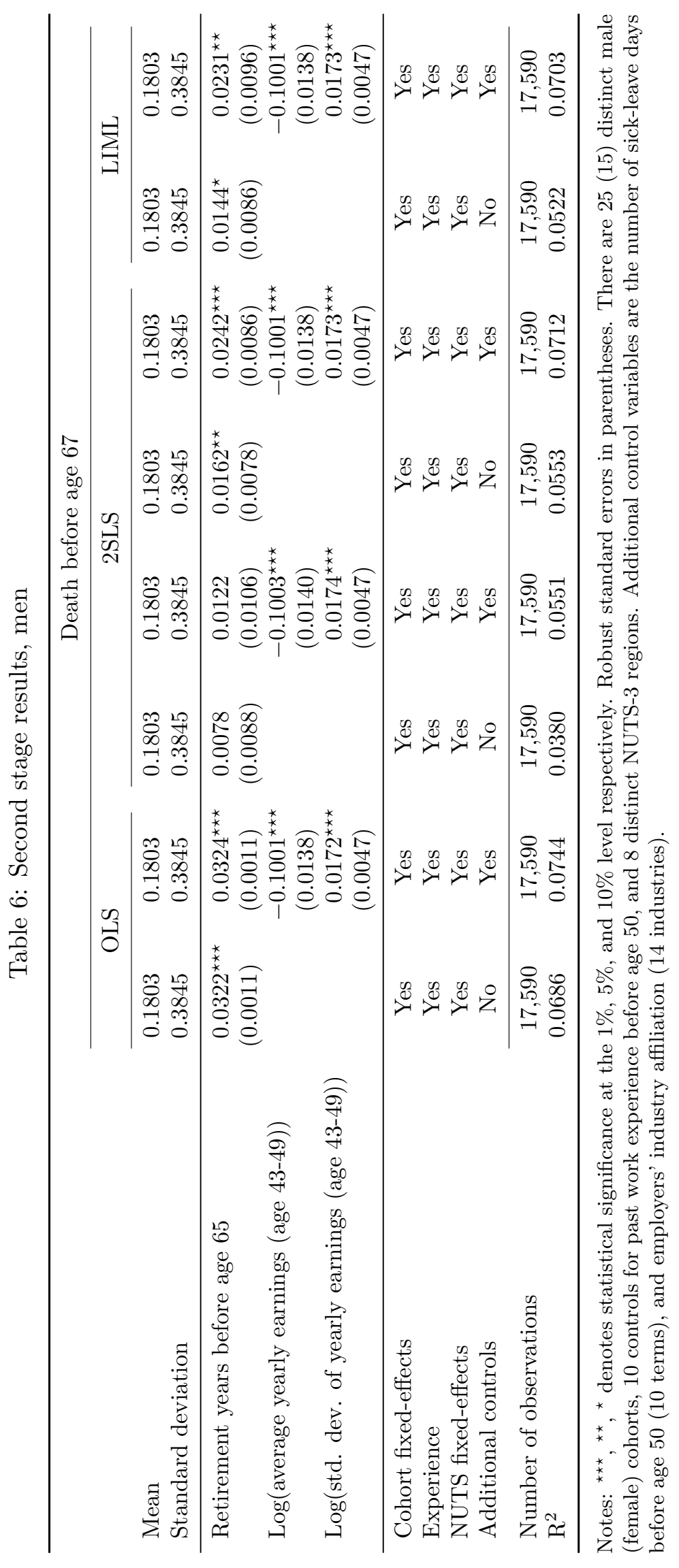




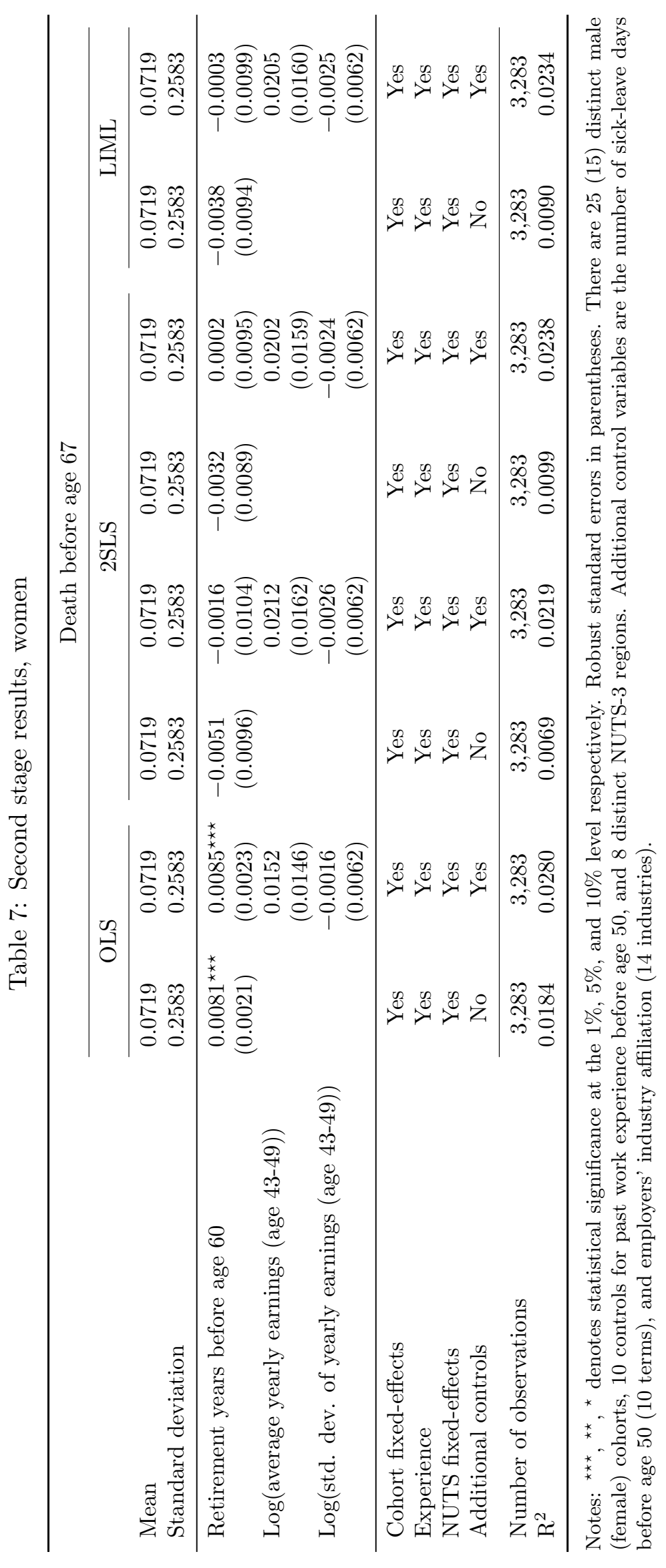




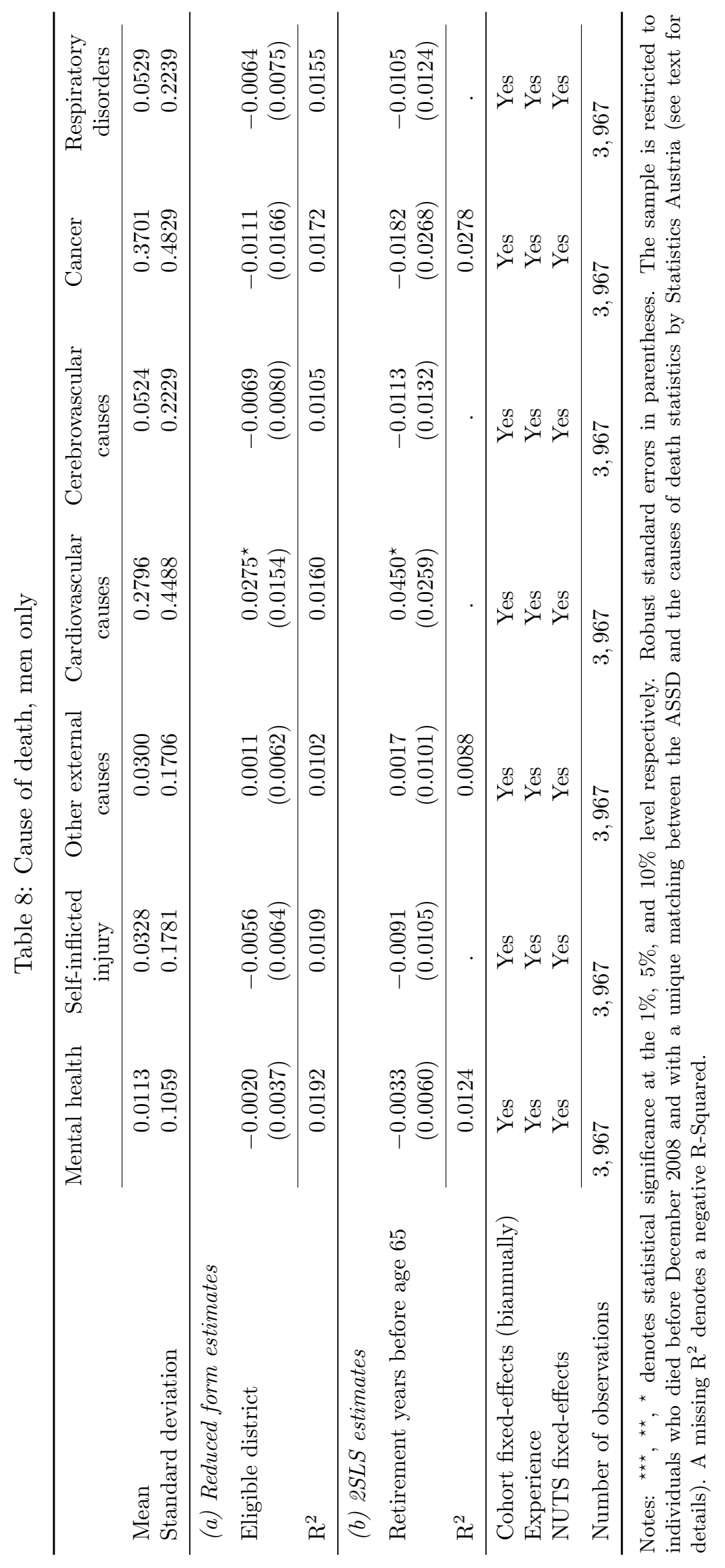




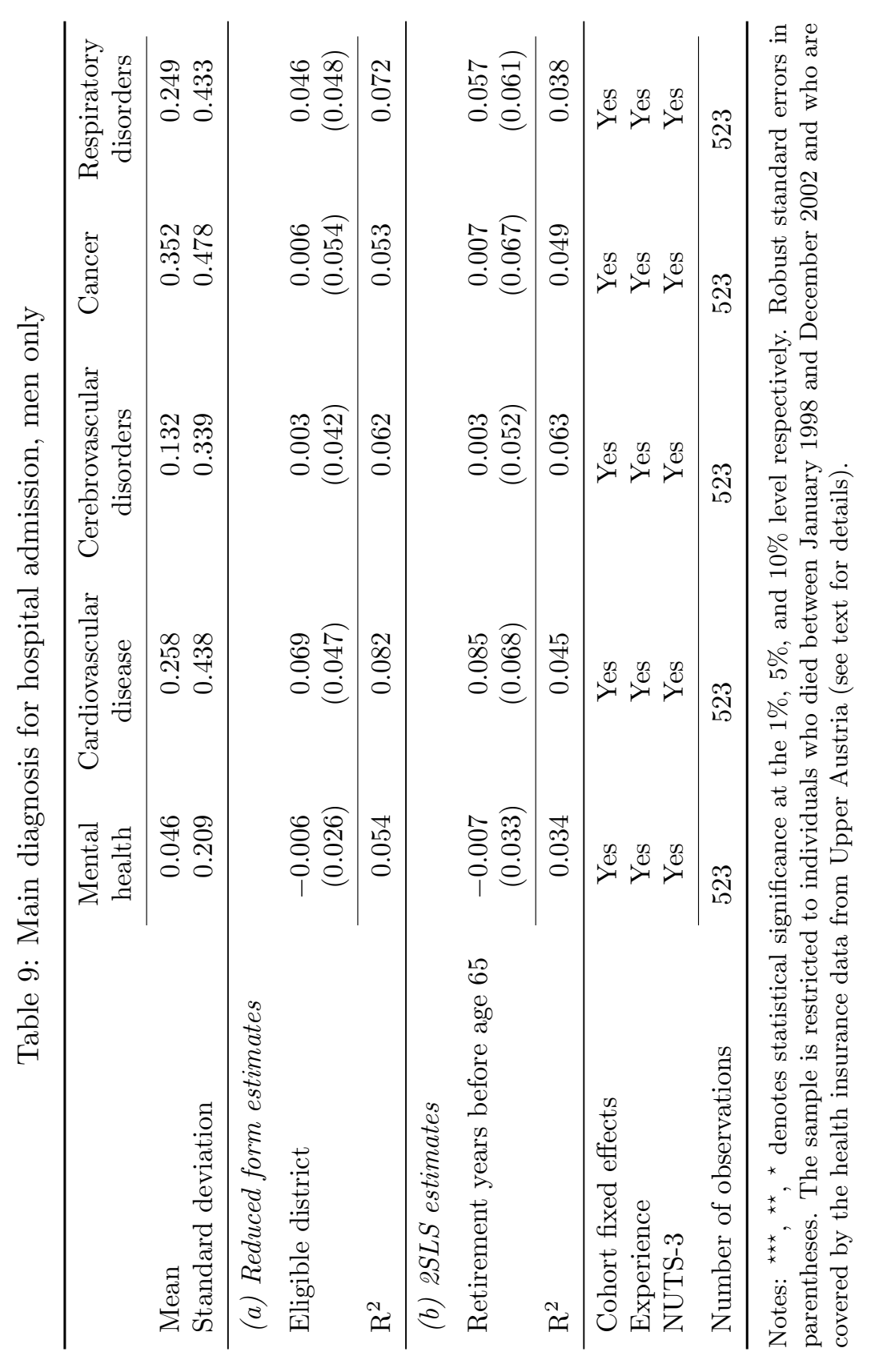




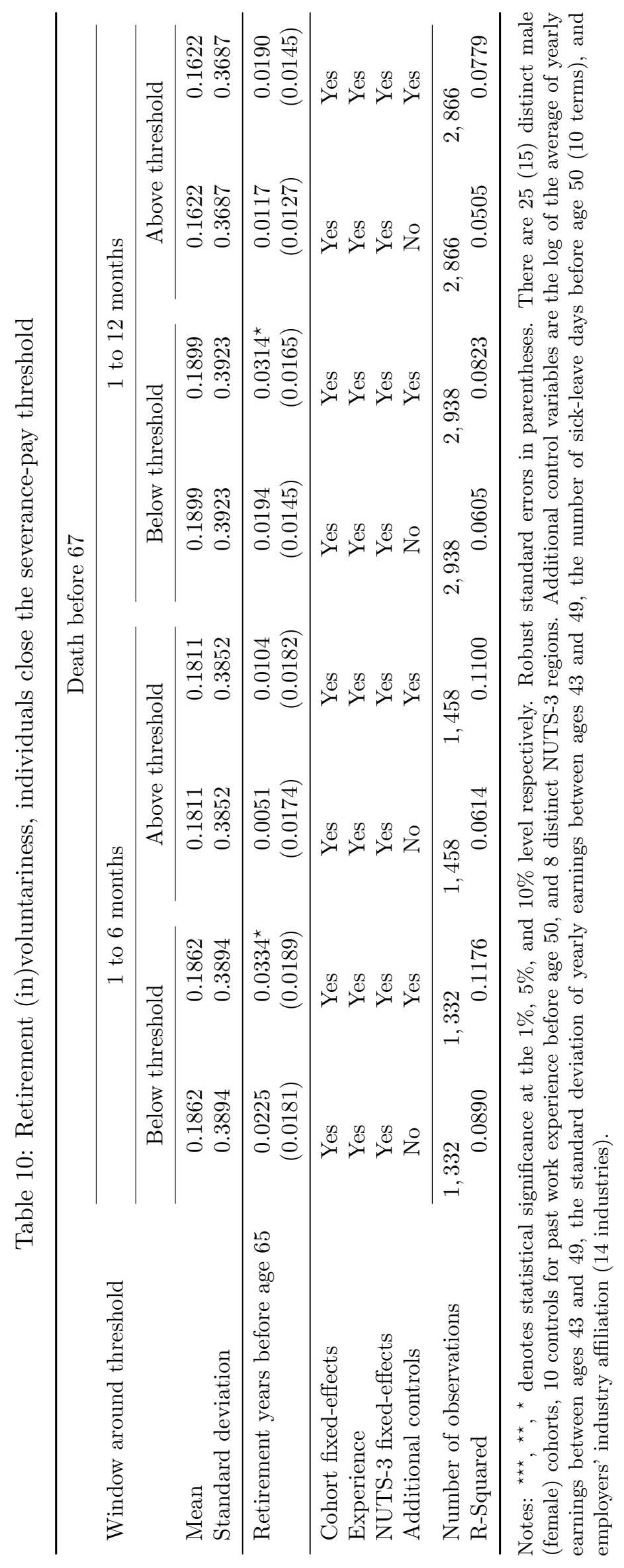




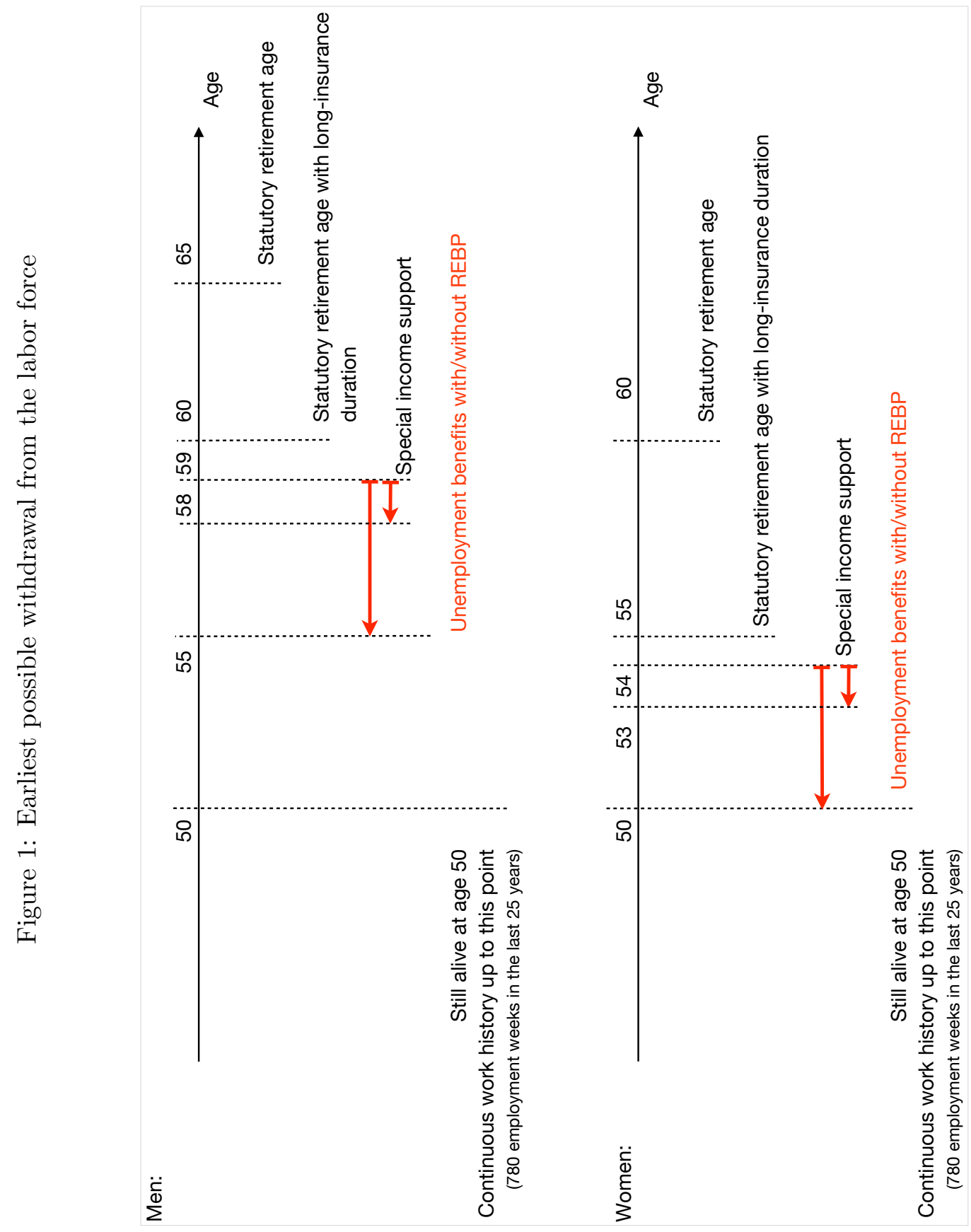




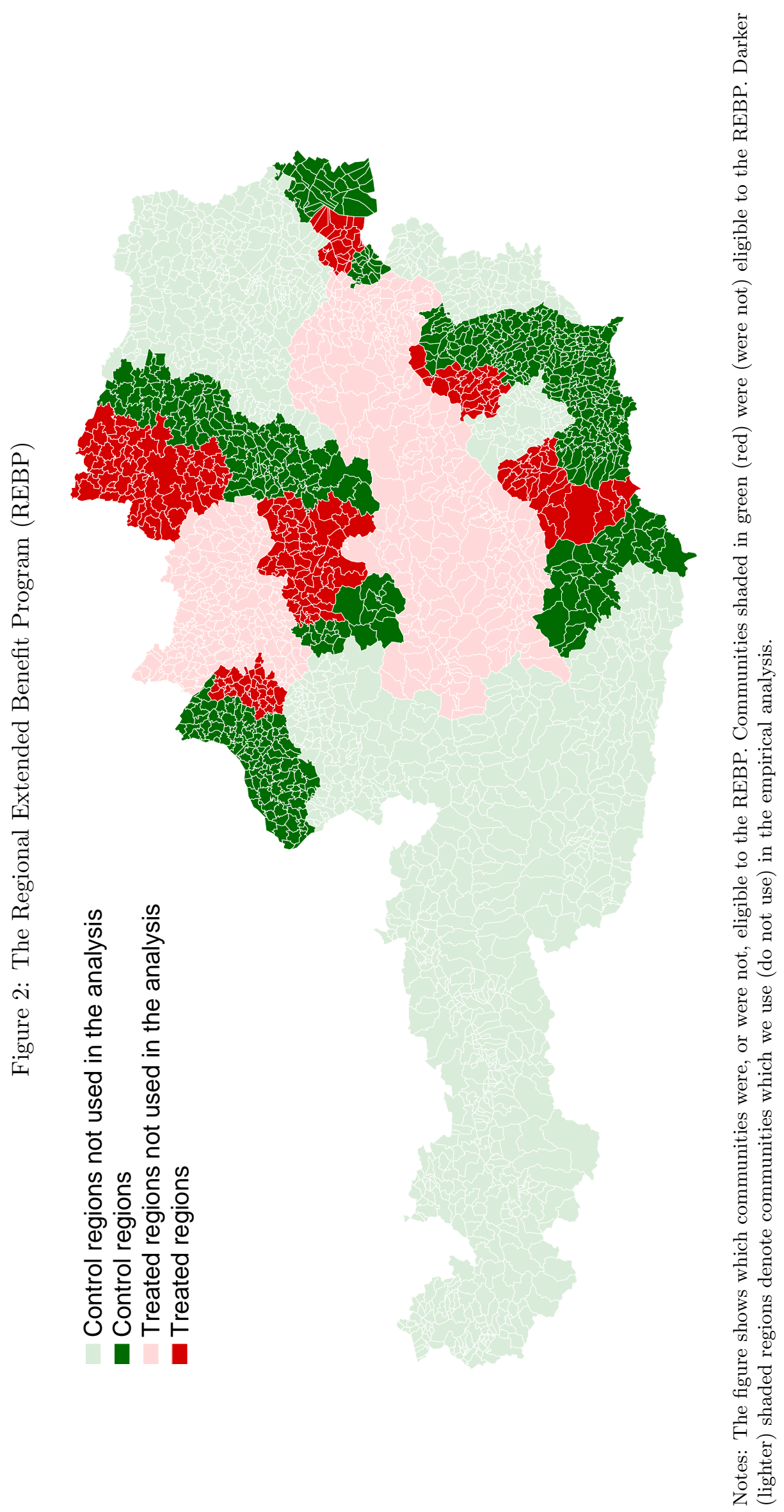


Figure 3: Fist-stage results

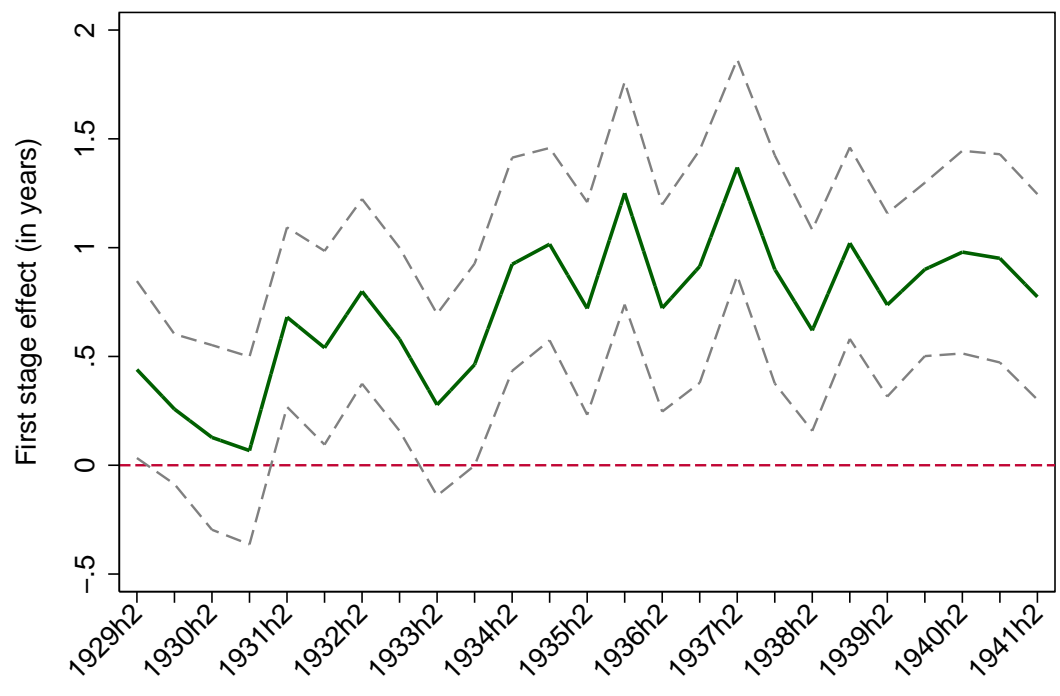

Birth cohort

(a) Men

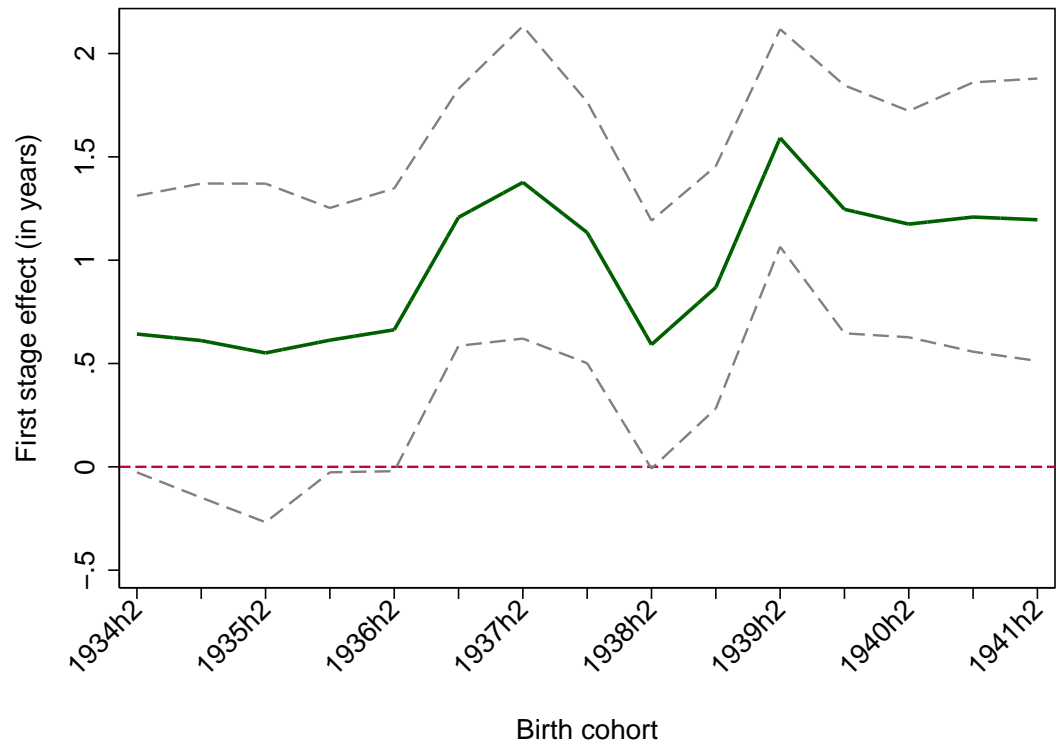

(b) Women

Notes: The figures plot the difference in the retirement age between eligible and non-eligible districts by year-semester birth-cohort in the sample of male and female workers, respectively. Dashed lines show $95 \%$ confidence bands. 
Figure 4: Treatment intensity

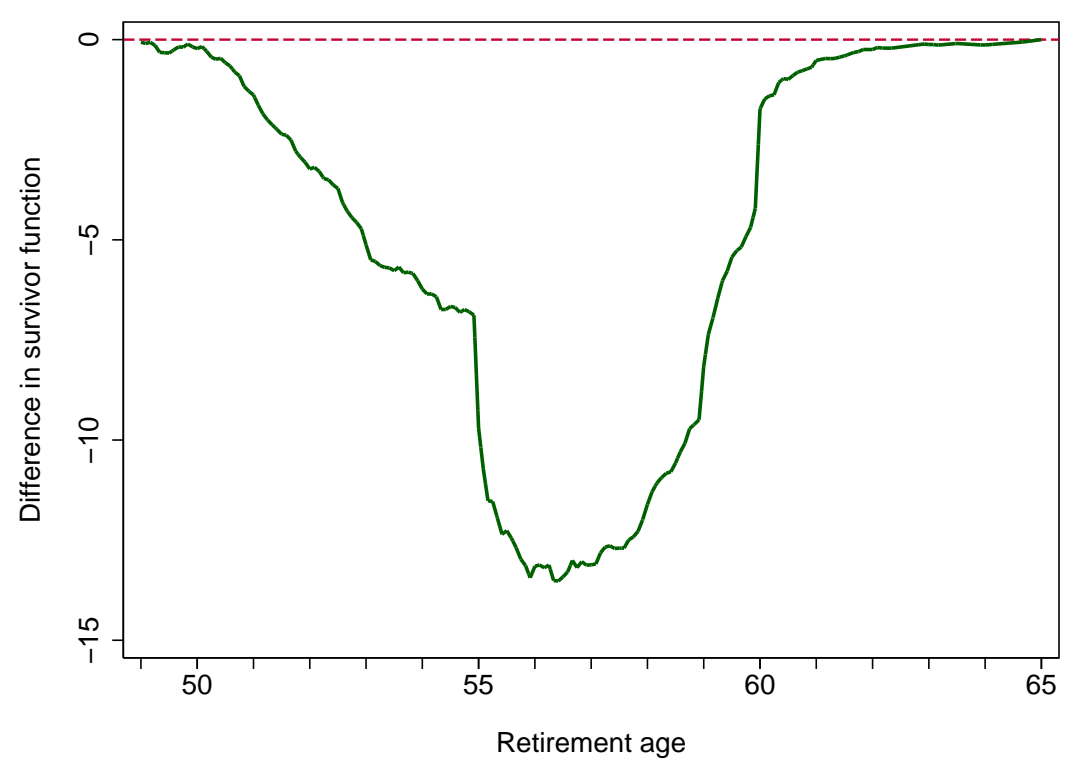

(a) Men

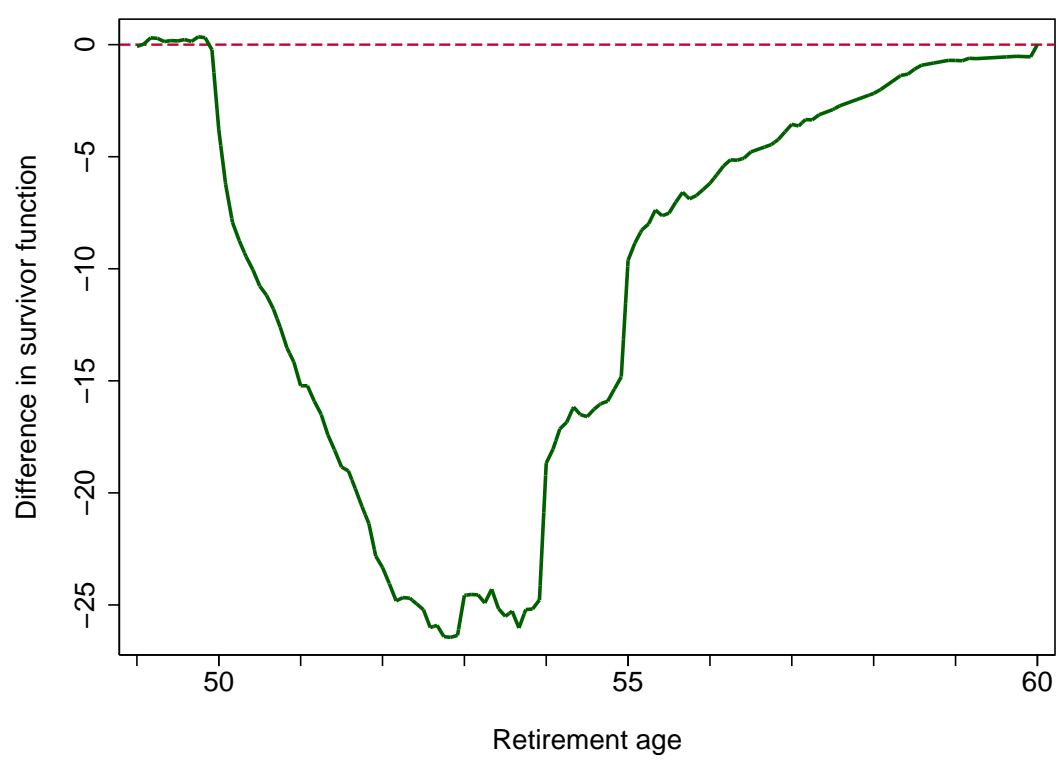

(b) Women

Notes: The figures show the difference in the survivor function (i.e. the probability of still being employed at a given age) between individuals from eligible and non-eligible regions. 


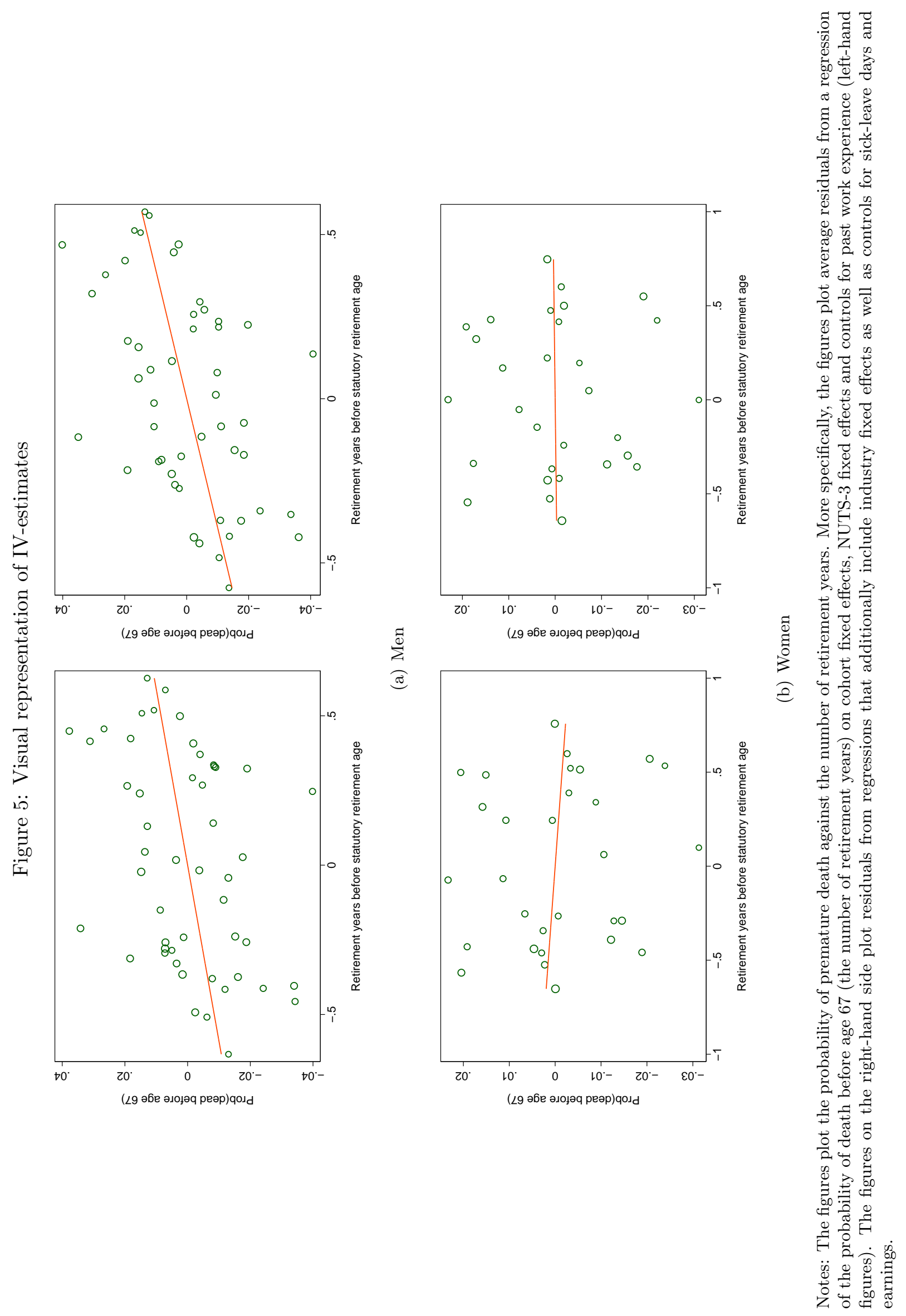




\section{A Additional Tables and Figures}

Table A.1: First stage results for cohorts ineligible to the REBP

\begin{tabular}{lcc}
\hline & Men & Women \\
\cline { 2 - 3 } Mean & 8.2685 & 5.3875 \\
Standard deviation & 3.4948 & 2.1897 \\
\hline Eligible district & -0.0071 & 0.0791 \\
& $(0.1115)$ & $(0.0800)$ \\
\hline Cohort fixed-effects & Yes & Yes \\
Experience & Yes & Yes \\
NUTS fixed-effects & Yes & Yes \\
Additional controls & Yes & Yes \\
\cline { 2 - 3 } Number of Observations & 3,444 & 3,005 \\
$\mathrm{R}^{2}$ & 0.2397 & 0.1876 \\
\hline
\end{tabular}

Notes: ${ }^{\star \star \star},{ }^{\star \star},{ }^{\star}$ denotes statistical significance at the $1 \%, 5 \%$, and $10 \%$ level respectively. Robust standard errors in parentheses. Considered birth cohorts are 08.1943-04.1947 for men and 08.1943-04.1952 for women. There are 25 (15) distinct male (female) cohorts, 10 controls for past work experience before age 50, and 8 distinct NUTS-3 regions. Additional control variables are the log of the average of yearly earnings between ages 43 and 49 , the standard deviation of yearly earnings between ages 43 and 49, the number of sick-leave days before age 50 (10 terms), and employers' industry affiliation (14 industries). 
Table A.2: The association between earnings from age 50 onwards and early retirement

\begin{tabular}{lcc}
\hline & \multicolumn{2}{c}{ Earnings from age 50 onwards } \\
\cline { 2 - 3 } Mean & 9.7237 & 9.7237 \\
Standard deviation & 0.3540 & 0.3540 \\
\hline Retirement years before age 65 & $-0.0222^{\star \star \star}$ & $-0.0250^{\star \star \star}$ \\
& $(0.0011)$ & $(0.0010)$ \\
\hline Cohort fixed-effects & Yes & Yes \\
Experience & Yes & Yes \\
NUTS-3 fixed-effects & Yes & Yes \\
Additional controls & No & Yes \\
Number of observations & 17,590 & 17,590 \\
$\mathrm{R}^{2}$ & 0.3141 & 0.6223 \\
\hline
\end{tabular}

Notes: ${ }^{\star \star \star},{ }^{\star \star},{ }^{\star}$ denotes statistical significance at the $1 \%, 5 \%$, and $10 \%$ level respectively. Robust standard errors in parentheses. Mean earnings derived from work income, unemployment benefits (assuming a replacement rate of $40 \%$ ), and disability and old-age retirement (assuming a replacement rate of $80 \%$ ) are estimated up to individuals' death date (right-censored death dates (July 1, 2009) are replaced by the expected death date based on workers' expected life-expectancy (taken from mortality tables by Statistics Austria). There are 25 (15) distinct male (female) cohorts, 10 controls for past work experience before age 50, and 8 distinct NUTS-3 regions. Additional control variables are the log of the average of yearly earnings between ages 43 and 49 , the standard deviation of yearly earnings between ages 43 and 49, the number of sick-leave days before age 50 (10 terms), and employers' industry affiliation (14 industries). 


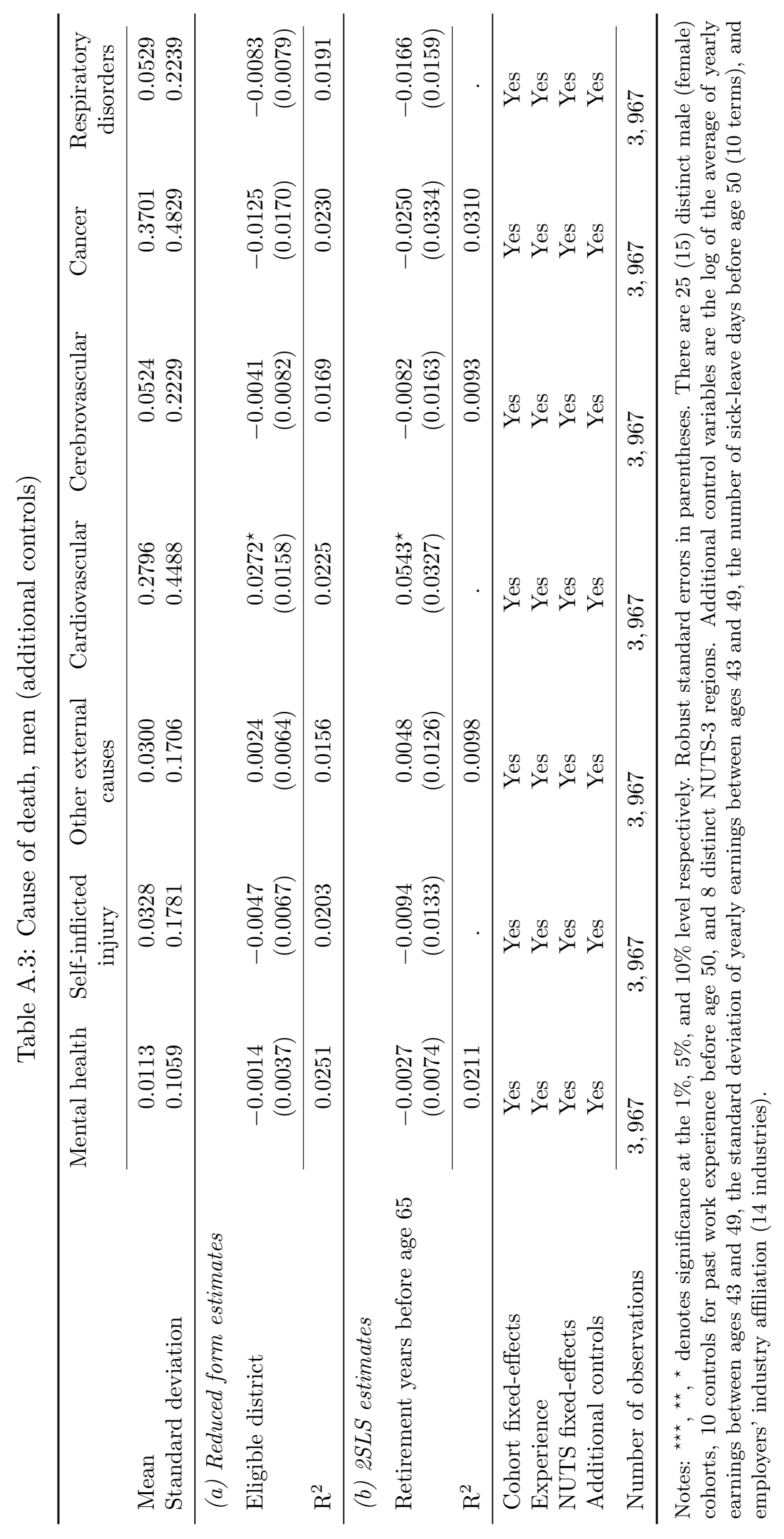




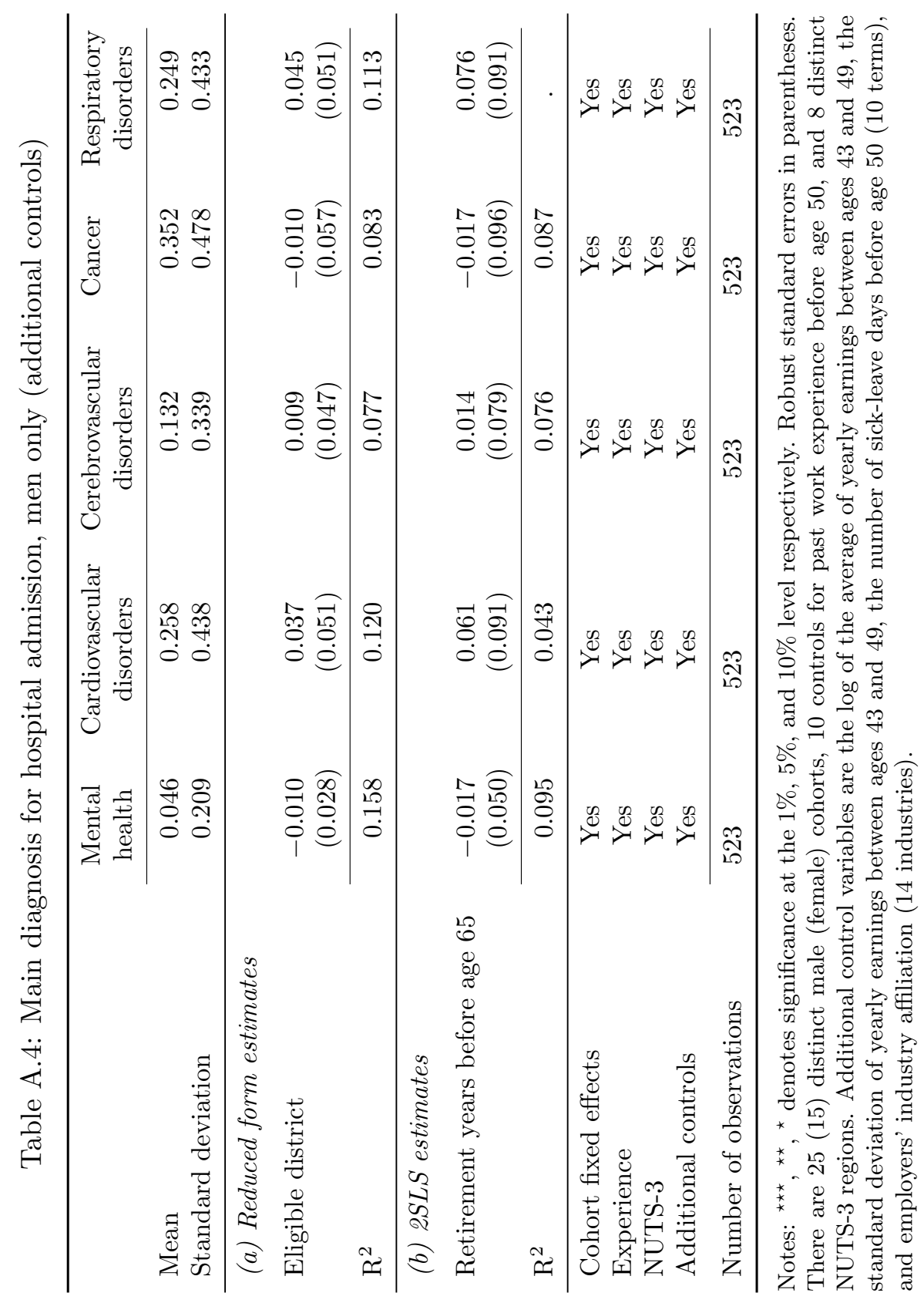




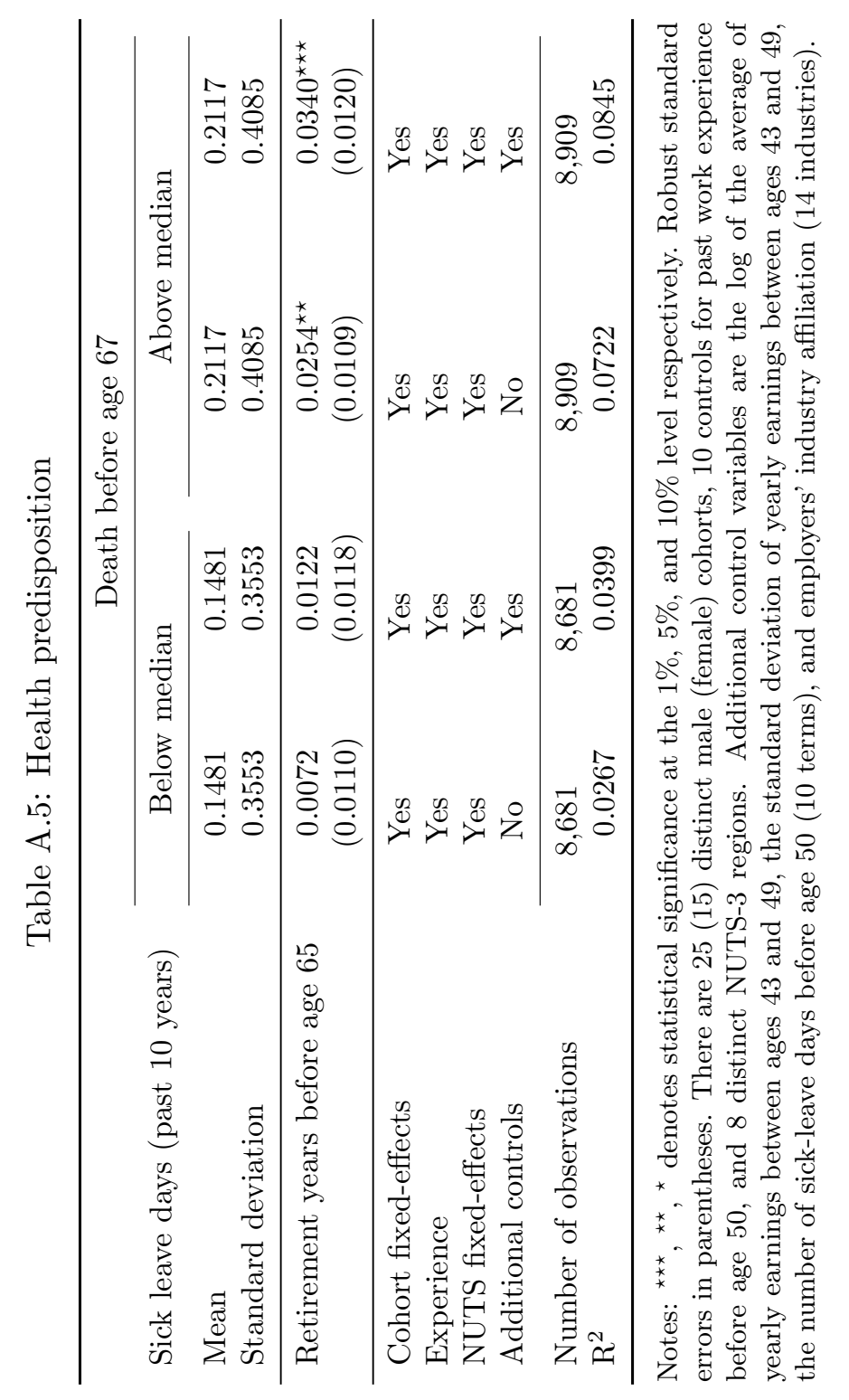



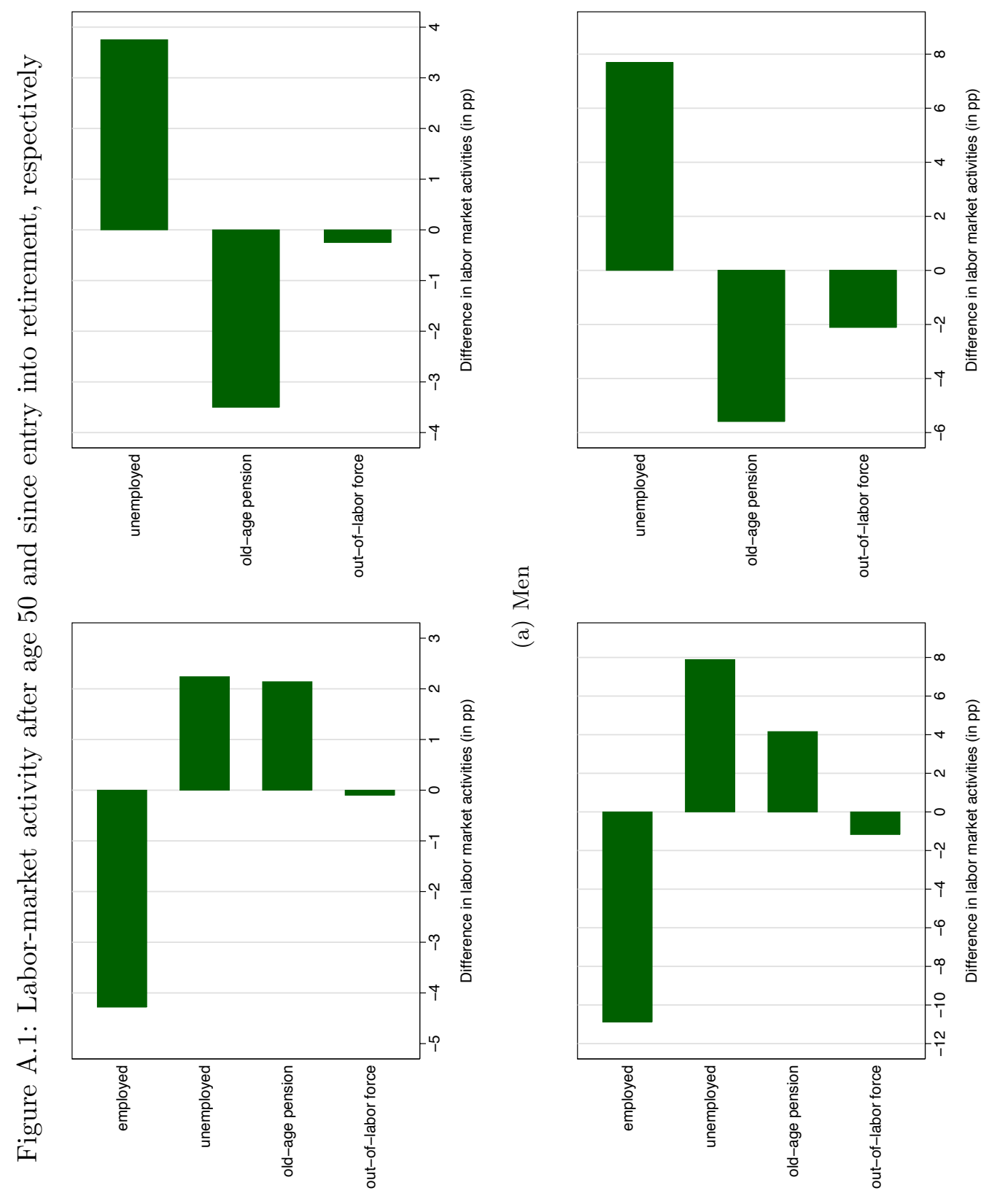

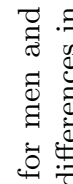

s

:

80.

苞

훙

$\exists$

苍毞

吾苛

苋

$\because 5$

을 